\title{
Therapeutic Deep Brain Stimulation Disrupts Subthalamic Nucleus Activity Dynamics in Parkinsonian Mice
}

Jonathan S Schor ${ }^{1,3,4}$, Isabelle Gonzalez Montalvo ${ }^{1,3,4}$, Perry W E Spratt ${ }^{1,3,4}$, Rea J Brakaj ${ }^{2,3,4}$, Jasmine A Stansil|,3,4, Kevin $J$ Bender ${ }^{1,2,3,4}$, and Alexandra $B$ Nelson ${ }^{1,2,3,4,5}$,*

${ }^{1}$ Neuroscience Program, University of California, San Francisco, San Francisco, CA 94158, USA

2Department of Neurology, University of California, San Francisco, San Francisco, CA 94158, USA

${ }^{3}$ Kavli Institute for Fundamental Neuroscience, University of California, San Francisco, San Francisco, CA 94158, USA

${ }^{4}$ Weill Institute for Neuroscience, University of California, San Francisco, San Francisco, CA 94158, USA

5Lead Contact

*Correspondence: alexandra.nelson@ucsf.edu 


\begin{abstract}
Subthalamic nucleus deep brain stimulation (STN DBS) relieves many motor symptoms of Parkinson's Disease (PD), but its underlying therapeutic mechanisms remain unclear. Since its advent, three major theories have been proposed: (1) DBS inhibits the STN and basal ganglia output; (2) DBS antidromically activates motor cortex; and (3) DBS disrupts firing dynamics within the STN. Previously, stimulation-related electrical artifacts limited mechanistic investigations using electrophysiology. We used electrical artifact-free calcium imaging to investigate activity in basal ganglia nuclei during STN DBS in parkinsonian mice. To test whether the observed changes in activity were sufficient to relieve motor symptoms, we then combined electrophysiological recording with targeted optical DBS protocols. Our findings suggest that STN DBS exerts its therapeutic effect through the disruption of STN dynamics, rather than inhibition or antidromic activation. These results provide insight into optimizing PD treatments and establish an approach for investigating DBS in other neuropsychiatric conditions.
\end{abstract}




\section{Introduction}

The basal ganglia are a group of interconnected subcortical structures long believed to control movement through modulation of neuronal firing. This rate-based model posits that reductions in basal ganglia output (globus pallidus interna [GPi] and substantia nigra pars reticulata $[\mathrm{SNr}])$ facilitate movement. According to this model, the loss of dopaminergic input to the basal ganglia in Parkinson's disease (PD) leads to pathological increases in GPi/SNr firing and impaired movement. Dopamine replacement therapies, such as with dopamine agonists or the dopamine precursor levodopa, reduce GPi/SNr firing in both PD patients and animal models (Hutchinson et al., 1997; Levy et al., 2001; Lozano et al., 2000; Papa et al., 1999), suggesting they may act by restoring normal firing rates. Given these findings and the rate model, it is paradoxical that deep brain stimulation (DBS) of the subthalamic nucleus (STN), an intrinsic basal ganglia nucleus with predominantly excitatory projections to $\mathrm{GPi} / \mathrm{SNr}$, is one of the most effective treatments for PD (Hickey and Stacy, 2016).

Investigations into how STN DBS impacts STN, GPi, and SNr activity have yielded conflicting results, and thus, how STN DBS exerts its therapeutic effects remains unclear. However, three major theories have been suggested (Chiken and Nambu, 2014): (1) STN DBS inhibits STN activity, consistent with the rate model; (2) STN DBS bypasses basal ganglia output by antidromically exciting cortical neurons projecting to the STN; or (3) STN DBS disrupts movement-related dynamics in the STN. Supporting (1), focal STN lesions relieve motor symptoms of PD (Andy et al., 1963; Bergman et al., 1990), and some groups have observed inhibition of STN, GPi, or SNr firing during DBS (Filali et al., 
2004; Moran et al., 2011). However, other groups have observed excitation in these structures (Hashimoto et al., 2003; Reese et al., 2011). Supporting (2), antidromic activation of primary motor cortex (M1) during STN DBS has been observed in rodents and in humans (Li et al., 2012; Miocinovic et al., 2018), and optical stimulation of hyperdirect M1 neurons relieves motor symptoms in parkinsonian mice (Gradinaru et al., 2009; Sanders and Jaeger, 2016). However, recent evidence in nonhuman primates shows antidromic M1 activation during electrical STN DBS to be both variable and transient, suggesting this pathway may not be the primary mechanism of STN DBS (Johnson et al., 2020). Supporting (3), correlations have been found between parkinsonian motor symptoms and signals such as local field potential (LFP) oscillations (Kühn et al., 2008; Stein and Bar-Gad, 2013; Wingeier et al., 2006) and bursting (Pan et al., 2016; Zhuang et al., 2018). Despite these observations, it has been difficult to distinguish between these possible mechanisms using electrophysiology, or to causally link observed changes in pattern and rhythm with improvements in behavior, in part due to large DBS-related electrical artifacts in recordings near the DBS site.

Here we used the genetically encoded calcium indicator GCaMP to enable regionand cell type-specific (and electrical artifact-free) optical recording of neural activity in three basal ganglia circuit nodes (STN, SNr, and M1) in a mouse model of STN DBS for PD. Surprisingly, we found that STN DBS increased activity in the STN and the SNr (in conflict with the rate model), and though DBS also altered hyperdirect pathway M1 activity, these changes did not correlate strongly with motor improvement. Furthermore, M1 lesions did not eliminate the therapeutic benefit of STN DBS. Finally, we found that DBS 
abolished stereotyped patterns of STN activity around movement onset. An optical stimulation protocol that similarly attenuated this activity pattern was sufficient to improve movement, suggesting disruption of movement-related STN dynamics may be a core therapeutic mechanism of STN DBS. Together, our results suggest STN DBS causes specific disruptions in motor signals at the level of the STN, broadening our understanding of how the basal ganglia mediates motor control.

\section{Results}

\section{STN GCaMP signals correlate with spiking measured by electrophysiology}

To test whether DBS inhibits, excites, or disrupts its target neurons, we used fiber photometry to measure bulk fluorescence signals from the genetically encoded calcium indicator GCaMP6s. To validate this approach, we first sought to determine whether STN calcium signals could serve as proxy for neural activity. We injected VGlut2-Cre mice with AAVs encoding Cre-dependent GCaMP6s, limiting expression to glutamatergic neurons within the STN. We then performed simultaneous whole-cell current-clamp recordings and fluorescence imaging of STN neurons in ex vivo slices to compare firing rate and intracellular calcium signals (Fig. 1A-C). Neurons were stimulated with current pulses at frequencies ranging from $10 \mathrm{~Hz}$ to $120 \mathrm{~Hz}$ in 1-minute epochs, which evoked rhythmic spiking corresponding to the frequency of stimulation (Fig. 1D-E). Calcium, as measured by changes in GCaMP6s fluorescence, similarly increased during stimulation at 10-120 $\mathrm{Hz}$, though notably in a non-linear fashion, suggesting a weaker correspondence between spiking and calcium at the highest stimulation frequencies (Fig. 1F-G). This phenomenon 
may also be related to limitations in GCaMP6s signaling at high intracellular calcium levels. In a subset of recordings, we assessed GCaMP6s signals in response to a range of lower stimulation frequencies $(10-60 \mathrm{~Hz})$. Again, STN neurons showed rhythmic spiking that matched the frequency of pulsatile stimulation (Fig. 1E, inset), and calcium signals correlated with firing rates (Fig. 1G, inset). In response to constant current ("square wave") stimulation, STN neurons fired only transiently, appearing to enter depolarization block (Fig. 1D-E). Under these circumstances, evoked calcium signals fell between those evoked by 10 and 50-60 Hz stimulation (Fig. 1F-G). These experiments suggest that the relationship between spiking and GCaMP calcium signals may break down at very high frequencies of stimulation, or under conditions of forced depolarization block. However, at the more moderate frequencies explored here, GCaMP calcium signals correlate with STN firing.

We next tested whether changes in bulk GCaMP6s fluorescence, as recorded through in vivo fiber photometry, corresponded with in vivo single-unit activity. To address this question, we recorded neural activity in vivo in two sets of parkinsonian animals, using either electrophysiology or calcium imaging. We rendered mice parkinsonian through unilateral injection of 6-OHDA in the medial forebrain bundle (MFB, Supplementary Fig. 1A). In one group of parkinsonian mice, we implanted a 16-channel electrode array in the ipsilateral STN (Fig. 1H). In a second group of parkinsonian VGlut2-Cre mice, we injected Cre-dependent GCaMP6s and implanted an optical fiber in the ipsilateral STN (Fig. 1I). As observed in prior 6-OHDA studies (Bové and Perier, 2012; Campos et al., 2013; Carvalho et al., 2013; Ungerstedt, 1968), these mice showed both decreased movement 
velocity $\left(1.3 \pm 0.1 \mathrm{~cm} / \mathrm{s}\right.$ parkinsonian vs $3.1 \pm 0.4 \mathrm{~cm} / \mathrm{s}$ healthy, $\left.P=8.23 \times 10^{-5}\right)$ and an ipsilesional rotational bias $\left(P=1.40 \times 10^{-3}\right)$ when compared to healthy mice (Supplementary Fig. 1B). Additionally, movement velocity and rotation bias did not differ significantly between parkinsonian mice with and without STN implants (Supplementary Fig. 1B, $P=0.66$ for velocity, $P=0.97$ for rotation), suggesting local, implant-related STN tissue disturbance did not alter gross movement parameters. We then aligned single-unit spiking activity and fiber photometry signal to movement starts (defined as a transition from velocity $<0.5 \mathrm{~cm} / \mathrm{s}$ to $>2 \mathrm{~cm} / \mathrm{s}$ ) in both sets of mice (Fig. 1J-K). STN single units showed baseline firing rates of approximately 5-10 spikes/s (Fig. 1J), well within the linear range for GCaMP6s (Fig. 1G, inset). The firing of STN units showed a marked change in firing rate around movement onset, increasing just prior to, and peaking just following movement initiation (approximately 1 spike/s over the baseline rate). Population calcium signals showed a similar increase around movement onset, but lagged the rise in singleunit firing rate by $\sim 1 \mathrm{sec}$, likely due to the slower kinetics of GCaMP6s (Markowitz et al., 2018) (Fig. 1K). Thus, STN calcium signals and electrophysiology appear to capture a slightly time-shifted, but qualitatively similar increase in activity when aligned to behavior. Together, these ex vivo and in vivo experiments show a correlation between spiking and GCaMP6s signal, and therefore support the utility of fiber photometry as a proxy for neuronal activity in the context of STN DBS. 


\section{STN DBS consistently increases STN activity}

The direct impact of STN DBS on STN neural activity remains unclear: some studies indicate STN DBS decreases STN firing rates, while recordings in downstream nuclei indicate STN activity may increase. To address whether STN DBS increases or decreases overall STN activity, we injected parkinsonian VGlut2-Cre mice with Credependent GCaMP6s and implanted them with both an STN DBS device and an optical fiber (Fig. 2A-B, Supplementary Fig. 2A,3A). Consistent with our previous findings in the same mouse model (Schor and Nelson, 2019), electrical STN DBS improved multiple movement metrics (Supplementary Fig. 2B-K). At either 60 or $100 \mathrm{~Hz}$ stimulation, STN DBS increased movement velocity (Supplementary Fig. 2B,C,G,H; $P=3.92 \times 10^{-9}$ for $60 \mathrm{~Hz}$, $P=5.53 \times 10^{-8}$ for $100 \mathrm{~Hz}$ ) and percent time moving (Supplementary Fig. 2D, I; $P=3.53 \times 10^{-}$ 9 for $60 \mathrm{~Hz}, P=1.46 \times 10^{-8}$ for $100 \mathrm{~Hz}$ ), while not significantly altering rotation bias (Supplementary Fig. 2E,J; $P=0.71$ for $60 \mathrm{~Hz}, P=0.47$ for $100 \mathrm{~Hz}$ ) or causing prolonged dyskinesias (Supplementary Fig. 2F,K). We subsequently used movement velocity as the primary behavioral outcome measure for STN DBS. We then measured changes in STN activity in vivo in response to treatment with STN DBS. Surprisingly, in parallel with its impact on movement velocity $\left(P=7.11 \times 10^{-9}\right)$, STN DBS at $60 \mathrm{~Hz}$ caused a significant increase in STN calcium signals (Fig. 2C-D, Supplementary Fig. 3B; $P=1.19 \times 10^{-7}$ ). The same was true for stimulation at $100 \mathrm{~Hz}$, with an increase in STN activity $\left(P=9.54 \times 10^{-7}\right)$ mirroring an increase in velocity (Fig. 2E-F, Supplementary Fig. $\left.3 \mathrm{C} ; P=1.11 \times 10^{-9}\right)$. This result suggests that, rather than inhibiting the STN, STN DBS increases STN activity. 
These results appear to conflict with the proposed inhibitory mechanism of other Parkinson's disease treatments, such as surgical ablations and dopamine replacement therapy. To compare how STN DBS and dopamine replacement therapy impact STN activity, we next evaluated the effects of levodopa administration on STN activity. In the same set of mice used for testing STN DBS, levodopa increased movement velocity (Supplementary Fig. 2L-M; $P=9.69 \times 10^{-10}$ ) and percent time moving (Supplementary Fig. $2 \mathrm{~N} ; P=9.56 \times 10^{-10}$ ), evoked contralesional rotations (Supplementary Fig. $2 \mathrm{O} ; P=1.73 \times 10^{-}$ $\left.{ }^{6}\right)$, and caused minimal dyskinesias (Supplementary Fig. 2P). We subsequently used movement velocity and rotation bias as primary and secondary behavioral outcome measures of levodopa treatment, respectively. In these sessions, though all mice showed improvements in movement $\left(P=1.66 \times 10^{-3}\right.$ for velocity, $P=3.91 \times 10^{-3}$ for rotation bias), changes in STN calcium were variable (Fig. 2G-H; Supplementary Fig. 3D). In some mice, STN activity decreased, while in others it increased: STN activity was not significantly changed across the entire group (Fig. $2 \mathrm{H} ; P=0.90$ ). Injection with saline did not improve movement parameters, nor did it produce significant changes in STN activity (Supplementary Fig. 3E-F; $P=0.084$ ). As levodopa does not produce electrical artifacts like DBS, we were able to compare its effects on both calcium signals and single-unit firing rates using electrophysiology. In parallel with its impact on movement $\left(P=3.13 \times 10^{-}\right.$ ${ }^{4}$ for velocity, $P=9.77 \times 10^{-4}$ for rotation bias), levodopa caused a modest, though significant, decrease in STN firing rates (Fig. 2I-J, Supplementary Fig. 3G; $P=0.029$ ). The fact that bulk calcium imaging did not detect the modest reductions in STN firing seen with electrophysiology may relate to differential sensitivity of the two methods. However, 
despite the fact that DBS and levodopa both improve movement parameters, they alter overall activity level in opposite directions.

\section{STN DBS increases SNr activity}

Though the STN is a critical node within the basal ganglia circuit, especially in regard to dysfunction in PD and its treatment, changes in STN activity are believed to regulate motor function via excitatory projections to basal ganglia output nuclei. In addition, STN DBS is likely to cause changes in the activity of nearby axons, and thus may have complex downstream effects. Therefore, while we did not observe inhibition at the level of the STN during STN DBS, we wondered if it might still produce inhibition at the level of the primary basal ganglia output nucleus in rodents, the substantia nigra pars reticulata (SNr). To determine how SNr activity responds to STN DBS, we injected either VGATCre mice with Cre-dependent GCaMP6s in the SNr (N=6 mice) or WT mice with synapsinGCaMP6s in the SNr ( $\mathrm{N}=2$ mice) and implanted them with an STN DBS device and an optical fiber in the SNr (Fig. 3A, Supplementary Fig. 4A). As before, STN DBS in these mice increased movement velocity (Fig. 3B-E; $P=1.33 \times 10^{-5}$ for $60 \mathrm{~Hz}, P=4.99 \times 10^{-6}$ for 100 $\mathrm{Hz}$ ). Consistent with our results in the STN, STN DBS (at both 60 and $100 \mathrm{~Hz}$ ) increased SNr activity (Fig. 3B-E; Supplementary Fig. 4B-C; $P=4.14 \times 10^{-5}$ for $60 \mathrm{~Hz}, P=3.32 \times 10^{-5}$ for $100 \mathrm{~Hz}$ ). Contrary to the basal ganglia rate model, and the inhibition theory of DBS, these findings suggest that both STN and SNr activity are increased by STN DBS.

To again validate calcium imaging signals and compare DBS to other treatments, we measured how levodopa altered SNr activity. In the same parkinsonian mice, levodopa 
increased movement velocity $(P=0.016)$ and caused a contralesional rotation bias (Fig. 3F-G; Supplementary Fig. 4D; $\left.P=7.81 \times 10^{-3}\right)$. In parallel, we observed a marked decrease in SNr neural activity as measured by calcium imaging (Fig. 3F-G; Supplementary Fig. 4D; $\left.P=6.68 \times 10^{-6}\right)$. In contrast, saline neither improved movement parameters nor significantly changed SNr calcium signals (Supplementary Fig. 4E-F; $P=0.31$ ). Single-unit electrophysiological recordings also showed profound reductions in SNr firing rate ( $P=0.012)$ during therapeutic levodopa treatment (Fig. 3H-I; Supplementary Fig. 4G), similar to findings in the GPi of parkinsonian nonhuman primates (Papa et al, 1999). Thus, calcium imaging and electrophysiology revealed qualitatively similar changes in SNr neural activity in response to levodopa, again supporting the idea that these two measures of neural activity have substantial concordance. Furthermore, these imaging experiments show marked differences in how STN DBS and levodopa impact neural activity, suggesting that STN DBS does not exert therapeutic effects through inhibition of STN or SNr.

\section{Hyperdirect Pathway Activity During STN DBS}

While we did not observe inhibition in either the STN or SNr during STN DBS, a more recent theory posits that STN DBS acts through antidromic activation of the hyperdirect pathway: primary motor cortex (M1) neurons that project monosynaptically to the STN. To assess whether STN DBS increases activity of hyperdirect M1 neurons, we imaged hyperdirect pathway neurons using a retrograde viral strategy. We injected the STN of parkinsonian mice with one of two retrograde viruses encoding Cre recombinase (CAV2- 
Cre or rAAV2-Cre-mCherry), and injected M1 with Cre-dependent GCaMP6s (Fig. 4A, Supplementary Fig. 5A-B). This strategy restricted expression of GCaMP6s to STNprojecting M1 neurons, which previously have been shown to send collaterals to the STN with parent axons in the cerebral peduncle (Kita and Kita, 2012) (Supplementary Fig. 5B). We then implanted an optical fiber in M1 and a DBS device in the STN. As in other parkinsonian mice, both 60 and $100 \mathrm{~Hz}$ STN DBS increased movement velocity (Fig. 4BE; $P=1.51 \times 10^{-9}$ for $60 \mathrm{~Hz}, P=4.14 \times 10^{-7}$ for $100 \mathrm{~Hz}$ ). Despite the consistent therapeutic effects of $60 \mathrm{~Hz}$ STN DBS (Fig. 4C, top), hyperdirect M1 calcium responses were surprisingly variable: some mice showed increases, while the calcium signal in other mice decreased or did not change (Fig. 4C, bottom; Supplementary Fig. 5C; $P=0.084$ ). In the same mice, $100 \mathrm{~Hz}$ STN DBS also produced consistent increases in movement velocity (Fig. 4E, top), but in this case M1 activity was more consistently increased during stimulation (Fig. 4E, bottom; Supplementary Fig. 5D; $P=5.88 \times 10^{-5}$ ). These results suggested poor correlation between hyperdirect M1 activity and the behavioral benefits of STN DBS. To further probe the correspondence between DBS effectiveness and hyperdirect M1 activation, we asked if the movement velocity of a single mouse during 60 $\mathrm{Hz}$ STN DBS could be predicted by that mouse's M1 calcium activity. We found that movement velocity during DBS did not correlate with change in hyperdirect M1 neural activity (Supplementary Fig. $5 \mathrm{E} ; \mathrm{R}^{2}=-0.14, P=0.96$ ). These findings suggest that while certain stimulation parameters may promote hyperdirect pathway activity, these changes do not strongly correlate with behavioral improvements during DBS. 
Additionally, we noted that increases in hyperdirect M1 activity evolved more slowly during STN DBS than increases in STN and SNr activity. The activity of neurons mediating the therapeutic effects of STN DBS would be predicted to change on a similar timescale to behavior. To compare the activation kinetics of STN, SNr, and hyperdirect M1 neurons during DBS, we measured the rise time of the calcium signal in regions and conditions in which we observed significant changes in neural activity: STN (60 and 100 $\mathrm{Hz})$, SNr (60 and $100 \mathrm{~Hz})$, and hyperdirect M1 (100 Hz). Given the observed lag between electrophysiology and bulk GCaMP signals seen by other groups (Markowitz et al., 2018), and in our own data (Fig. 1), we expected that changes in neural activity driving motor benefits (as measured with GCaMP) might appear to lag the behavior itself. Across all STN DBS conditions, the rise time for movement velocity averaged $2.8 \pm 0.6 \mathrm{sec}$. For each condition, we calculated the difference in rise time between the calcium signal and movement velocity as an indicator of whether these two signals changed on a similar timescale. STN calcium signals during $60 \mathrm{~Hz}$ or $100 \mathrm{~Hz}$ STN DBS lagged movement velocity by $2.6 \pm 1.1 \mathrm{sec}$. We observed a similarly short lag comparing SNr calcium signals to the corresponding movement velocity traces $(3.7 \pm 1.8 \mathrm{sec})$. However, the lag in hyperdirect M1 activity was markedly longer (17.3 $\pm 3.1 \mathrm{sec})$. These kinetics indicate STN and SNr activity evolve on a timescale similar to the movement benefits of STN DBS, while hyperdirect M1 activity, as measured by fiber photometry, evolves more slowly. 


\section{Surgical removal of M1 does not abolish therapeutic benefit of STN DBS}

Though overall hyperdirect pathway activity was not a strong predictor of the therapeutic effects of STN DBS, these findings do not exclude the possibility that the hyperdirect pathway mediates motor benefits. We next asked if M1 was required for the therapeutic effects of STN DBS on movement. We surgically removed the ipsilesional M1 of parkinsonian mice and implanted STN DBS devices (Fig. 5A, Supplementary Fig. 5F). As in previous motor cortex lesion studies (Kawai et al., 2015), mice were allowed to recover for at least 10 days before behavioral testing. Remarkably, these mice still showed a significant increase in movement velocity in response to $100 \mathrm{~Hz}$ STN DBS (Fig. 5B-C; $\left.P=8.24 \times 10^{-3}\right)$. Thus, it is unlikely that antidromic activation of $M 1$ is the primary driver of the therapeutic benefit of STN DBS in parkinsonian mice.

\section{STN movement-related activity is disrupted by therapeutic STN DBS}

Our results indicate that STN DBS is unlikely to work through inhibition of basal ganglia output, nor through antidromic excitation of M1. However, a third possibility is that STN DBS disrupts neural dynamics within the STN itself. As previously noted, in parkinsonian mice, STN activity increases around movement initiation (Fig. 6A, left), consistent with the idea that STN neurons encode some aspects of movement. To determine whether this encoding was altered during DBS, we aligned neural activity to movement starts during stimulation epochs. We found that although the overall average calcium signal was increased during DBS (Fig. 2), the movement-aligned increase in STN activity was 
abolished during therapeutic STN DBS at $100 \mathrm{~Hz}$ (Fig. 6A, right). This observation suggested that STN movement encoding was disrupted by STN DBS.

This disruption might result from any patterned electrical stimulation, or it could represent a direct correlate of therapeutic stimulation. To test these possibilities, we chose 13 parameter combinations (varying in current amplitude, frequency, and pulse width, Supplementary Table 2) from a set that we had used previously to evaluate the impact of STN DBS parameters on behavioral benefit in the mouse model (Schor and Nelson, 2019). In the same mice, we measured locomotor activity and calcium signals while delivering STN DBS at each of these 13 parameter combinations. Behavioral responses were divided into two groups, depending on whether the DBS-induced movement velocity averaged greater or less than $1 \mathrm{~cm} / \mathrm{s}$ (Fig. 6B). We labeled the first group "high effect" stimulation (8 combinations) and the second group "low effect" stimulation (5 combinations). We then assessed STN movement-related activity dynamics during each stimulation type, as measured by the peak-to-trough deflection of the movement-aligned STN photometry signal (Fig. 6C, shaded inset). Interestingly, across the 13 stimulation parameter sets, this neural activity metric showed a bimodal distribution. With low effect stimulation parameters, STN calcium signals increased around movement onset, as they did during baseline (no stimulation) periods. This resulted in a peak-to-trough change in calcium that was $>1$ (z-scored dF/F; Fig. 6C). However, during high effect stimulation, STN calcium signals changed minimally around movement onset, with a peak-to-trough change of $<1$ (Fig. 6C). When comparing STN activity across all high effect vs all low effect stimulation parameters rather than 
individually, normal movement-related STN dynamics were strongly suppressed only during highly effective stimulation (Fig. $6 \mathrm{D} ; P=1.48 \times 10^{-11}$ for pre vs. high, $P=0.54$ for pre vs low). Taken together, these results suggest that STN DBS disrupts movement-related STN dynamics and furthermore that this disruption is specific to behaviorally beneficial stimulation parameters.

\section{Disruption of STN motor dynamics is sufficient to provide therapeutic benefit}

STN DBS may trigger many changes in both the rate and dynamics of neural activity. However, it remains critical to determine which changes in neural activity causally contribute to the therapeutic mechanism(s) of STN DBS. In our experiments using electrical STN DBS, we observed changes in both overall STN activity and movementrelated dynamics, making it difficult to determine which change is more likely to mediate the benefit. To disentangle the behavioral impacts of changing STN rate and dynamics, we replaced electrical DBS/optical recording with optical DBS/electrical recording techniques. We injected parkinsonian VGlut2-Cre mice with Cre-dependent channelrhodopsin (ChR2) and implanted 16-channel optrode arrays in the STN (Fig. 7A, Supplementary Fig. 6A). We then assessed STN single-unit firing during two optical stimulation paradigms in freely moving parkinsonian mice: "constant" and "pulsatile" (50 $\mathrm{Hz}$ ) blue light stimulation (both $3 \mathrm{~mW}$ ). As has been observed previously in anesthetized STN recordings in rats (Yu et al., 2020), STN neurons showed both excitatory and inhibitory responses to optical stimulation (Fig. 7B-E; Supplementary Fig. 6B-C). However, both stimulation paradigms caused similar decreases in overall firing rate (Fig. $7 \mathrm{C}, \mathrm{E}$; 
$P=0.98$ comparing relative firing rates during constant and $50 \mathrm{~Hz}$ stimulation, Wilcoxon sign-rank test). Of note, the response of STN neurons to optical stimulation differed between in vivo/freely moving and ex vivo preparations. During cell-attached patch-clamp recordings of STN in ex vivo slices (Supplementary Fig. 6D), pulsatile $(50 \mathrm{~Hz})$ blue light stimulation increased STN firing fairly consistently (Supplementary Fig. 6E-F; $P=0.033$ ), while constant illumination evoked more variable changes in spiking (Supplementary Fig. $6 \mathrm{G}-\mathrm{H} ; P=0.63)$. The effects of optical stimulation on STN firing in the in vivo, freely moving condition, however, are most relevant to the behavioral impact of STN DBS.

While both optical stimulation patterns produced decreases in the average firing rate of STN neurons, the two stimulation paradigms had different effects on movementrelated STN dynamics. During stimulation-off epochs for both paradigms, STN firing rate increased around the time of movement starts (Fig. 7F,G, left), as we had observed previously (Fig. 1J). During constant optical stimulation, these movement-related STN dynamics did not change significantly (Fig. $7 F$, right; $P=0.51$ ). In contrast, pulsatile $50 \mathrm{~Hz}$ stimulation greatly attenuated these dynamics (Fig. $7 G$, right; $P=0.039$ ). Based on these electrophysiological recordings, continuous and $50 \mathrm{~Hz}$ optical stimulation produce similar changes in firing rate, but distinct effects on dynamics, allowing us to disentangle the effects of STN rate and pattern in producing therapeutic effects in parkinsonian mice.

To test whether these two stimulation paradigms would produce different behavioral effects, we studied a larger cohort of parkinsonian VGlut2-Cre mice, injected with Cre-dependent ChR2 or eYFP (control) and implanted with optical fibers in the STN (Supplementary Fig. 6A). In different test sessions, we stimulated with either constant or 
pulsatile blue light in 1-minute epochs. We predicted that continuous stimulation, which did not alter STN dynamics, would not produce benefits, while pulsatile stimulation, which greatly attenuated STN dynamics, would increase movement velocity. During constant illumination, neither STN-ChR2 nor STN-eYFP mice showed a significant increase in movement velocity or other metrics such as percent time moving or change in rotation bias (Fig. 7H-I; Supplementary Fig. 6I-K; $P=0.30$ for ChR2 movement velocity, $P=0.66$ for eYFP movement velocity). However, STN-ChR2 mice receiving $50 \mathrm{~Hz}$ stimulation did show a significant increase in movement velocity and percent time moving (Fig. 7J-K; Supplementary Fig. 6L-M; $P=1.27 \times 10^{-8}$ for movement velocity, $P=5.56 \times 10^{-9}$ for percent time moving), similar to mice receiving electrical STN DBS, and also developed an increased bias towards ipsilesional rotations (Supplementary Fig. 6L (inset); $P=0.016$ ). STN-eYFP mice did not show a significant change in movement velocity during $50 \mathrm{~Hz}$ stimulation (Supplementary Fig. $6 \mathrm{~N} ; P=0.81$ ). These results demonstrate that although therapeutic electrical and optical STN DBS produce quite distinct changes on the rate of STN activity, they both disrupt movement-related STN dynamics. Moreover, they suggest that disrupting movement-related STN dynamics is sufficient to ameliorate parkinsonian motor deficits, making it a candidate mechanism for electrical STN DBS. 


\section{Discussion}

We combined a recently developed mouse model of electrical STN DBS for Parkinson's disease with electrical artifact-free GCaMP fiber photometry to investigate three major theories surrounding the mechanism of electrical STN DBS: (1) STN DBS inhibits STN and SNr activity; (2) STN DBS acts through antidromic activation of hyperdirect M1 neurons; and (3) STN DBS acts through disrupting neuronal activity patterns within the STN. We observed that STN DBS excites rather than inhibits the STN and SNr, and that M1 activation does not seem to be necessary for therapeutic STN DBS, rendering the first two theories less likely. In support of the third theory, we observed that therapeutic electrical stimulation abolished patterned STN activity around movement onset and used optical manipulations to demonstrate that attenuating STN dynamics may be causal in the motor benefits of DBS.

In this study, we used calcium imaging with GCaMP6s to examine how neural activity changes during STN DBS. A recent study demonstrated technical feasibility of using in vivo calcium imaging with electrical STN DBS (Trevathan et al., 2020), but ours is the first to use this approach to link DBS-mediated physiological changes to behavior in freely moving parkinsonian animals. Moreover, our study is one of the first to use fiber photometry in deep basal ganglia nuclei, and to compare these signals with in vivo singleunit electrophysiology. This approach had several advantages, as well as limitations. The key advantage was the ability to obtain recordings free from electrical artifacts. Artifacts had been a major obstacle in prior electrophysiological studies, particularly in studying the effect of DBS on neurons in the target structure, such as the STN or GPi. A second 
advantage was the ability to use cell type- or projection-specific techniques. For example, the use of retrograde viruses allowed us to target the direct projections from primary motor cortex to STN (hyperdirect pathway), a population of significant interest in PD and DBS. Though STN and SNr are relatively homogeneous structures, with regard to major neurotransmitters (Smith and Parent, 1988; Walaas and Fonnum, 1979), future studies could use GCaMP and genetics to target either specific STN/SNr projections, or novel cell types within them (Kita and Kitai, 1987; Liu et al., 2020). A disadvantage of our approach over electrophysiology, however, is its temporal resolution. While traditional single-unit electrophysiology can detect individual action potentials, calcium imaging with GCaMP provides an integrated signal arising from multiple spikes (Chen et al., 2013; Sabatini, 2019). Fiber photometry further averages across a population of neurons, making it challenging to detect more rapid events. Given this temporal lag, it is difficult to establish whether DBS-associated changes in GCaMP signal arise directly from electrical stimulation, network activation, sensory feedback, or all of the above. Nonetheless, our activity measurements with photometry showed striking similarities to activity measurements using single-unit electrophysiology, over both short (movement-aligned activity) and long (responses to systemic levodopa administration) timescales. There thus appears to be correspondence between the two recording techniques. In the future, voltage indicators with high signal-to-noise that are compatible with deep imaging, as well as miniscope imaging of many single neurons simultaneously, may allow detection of single spikes and help increase the information obtained in optical recordings during DBS. 
Our observation that therapeutic STN DBS increases activity at the level of the STN and $\mathrm{SNr}$, rather than inhibiting it, is at odds with traditional rate-based models of basal ganglia function. In fact, previous STN DBS electrophysiological studies in parkinsonian primates have had conflicting results: some show increased basal ganglia output activity during STN DBS, while others observe local STN inhibition (Filali et al., 2004; Moran et al., 2011). Single-unit data in rodents is more limited, but analyses of pattern at both the single-unit and LFP level in one study suggest that the therapeutic benefit of STN DBS may be independent from overall changes in STN firing rate (Zhuang et al., 2018). Thus, it is possible that treatments that increase (e.g. DBS) or decrease STN firing (e.g. optical inhibition (Yoon et al., 2014) or levodopa) may be therapeutic. Some discrepancies in existing physiological data may arise from the imperfect process of removing STN DBS artifacts from electrophysiological recordings, especially in structures like STN and SNr that have high spontaneous firing rates. Others may relate to differences among animal models of PD.

Electrical STN DBS may increase the activity of STN neurons via several physiological mechanisms. As electrical stimulation has previously been suggested to preferentially recruit axons (Mclntyre et al., 2004; Mclntyre and Grill, 1999; Nowak and Bullier, 1998), DBS may drive antidromic spiking of STN neurons via stimulation of efferent STN axons, as well as drive STN spiking via activation of incoming excitatory axons. Depending on the proximity of the electrode to neural elements, it may drive STN activity through local activation of dendrites or cell bodies, as well. Increased SNr spiking may be driven by orthodromic activation of STN to SNr excitatory axons, or potentially by more complex 
network effects. The time resolution of fiber photometry and the time lag between STN and $\mathrm{SNr}$ activation (on average about 1 second) with this method cannot exclude polysynaptic effects. It is important to note that calcium imaging data are correlative, and the behavior of mice during therapeutic STN DBS changes markedly. The change in movement may itself drive changes in STN and SNr activity, for example through sensory feedback to the basal ganglia. The recorded signals in the STN and SNr may therefore be both a cause and/or an effect of increased movement.

Though we observed modulation of hyperdirect M1 neurons during STN DBS, this modulation did not correlate well with therapeutic effects. While this is suggestive that the hyperdirect pathway is less important for the therapeutic effect of STN DBS, differences in the physiologic properties of M1 projection neurons, as compared to STN and SNr neurons, might have contributed to the late-developing changes in M1. However, removal of M1 did not abolish the therapeutic benefit of STN DBS, leading us to conclude that hyperdirect M1 activation may not play a central role. The discrepancy between our conclusions and those of previous studies has a number of potential explanations. While past mouse studies have used optogenetic stimulation as a proxy for electrical STN DBS (Gradinaru et al., 2009; Sanders and Jaeger, 2016), we used electrical stimulation in an effort to more closely model what is observed in PD patients (our eventual use of optogenetic stimulation was directly informed by our observations during electrical stimulation). The former approach identifies manipulations that are sufficient to relieve parkinsonian motor symptoms, while the latter identifies changes that correlate with a specific therapy. Thus, while optogenetic stimulation may reveal that changing neural 
activity in a variety of ways can relieve parkinsonism in mice, it is difficult to extrapolate which of these changes actually occur during electrical STN DBS. In other words, two therapies that have similar behavioral effects may not have the same mechanism of action. In addition, while hyperdirect pathway neurons did not seem to be crucial for the benefits of STN DBS in mice, using locomotor velocity as a primary outcome measure, they may play an important role in other species, or in the benefits of DBS in other motor domains.

In the absence of therapeutic manipulations, we found that STN neurons in parkinsonian mice show an increase in activity around movement initiation. Similar observations have been made in the STN of healthy NHPs and cats (Cheruel et al., 1996; Wichmann et al., 1994). Less is known about what drives this increase, though candidates include excitatory input from hyperdirect M1 neurons (Polyakova et al., 2020), inhibitory input from the globus pallidus pars externa (GPe) (Chu et al., 2015; Kovaleski et al., 2020), and/or increased synchronization among STN neurons. As we found that disruption of STN movement-related dynamics may play a role in alleviating parkinsonian symptoms, identifying the physiological sources of this signal will likely be an important question in future research.

Our observation that movement-related STN activity patterns are altered during STN DBS may relate to previous work showing changes in firing patterns or network synchrony during STN DBS. It has previously been postulated that rate-independent aspects of neural activity, such as within-neuron firing pattern or between-neuron synchronization, may drive PD symptoms and represent key markers of therapeutic interventions 
(Hammond et al., 2007; Little and Brown, 2014; Wichmann, 2019). Many other groups have observed increased oscillations throughout the basal ganglia in parkinsonian animal models and in humans, which may resolve with therapeutic treatment (de Hemptinne et al., 2015; Halje et al., 2012; Moran et al., 2012; Shimamoto et al., 2013). In fact, one group studying healthy NHPs has even observed positive modulation during movement in pallidal cells, similar to what we observed during movement starts in STN neurons, and which was similarly interrupted in a subset of pallidal neurons during STN DBS (Zimnik et al., 2015). The difficulty, though, has been in establishing a causal link between changes in these patterns during DBS and improvement in behavior. Our ability to not only observe, but also to trigger these changes through optogenetic manipulation helps fill this critical gap. Additional causal links might be investigated further in the future using a combination of optical and electrical methods, building on the approach introduced here.

Though it facilitated our use of cell type-specific methods and imaging tools, a key potential caveat of our study is the mouse model of PD. First, the 6-OHDA model causes focal, rapid, and in this case nearly complete loss of dopaminergic neurons and their projections. In contrast, PD causes neurodegenerative changes in multiple brain areas over many years. Though many key physiological features of PD are similar in toxinbased models of parkinsonism (Bové and Perier, 2012; Campos et al., 2013), others may be distinct based on the pattern and tempo of neurodegeneration. In addition, electrical stimulation may have different impacts in the small mouse brain as compared to the human brain. Though electrical stimulation is unlikely to respect the borders of brain nuclei in either species, the small size of the target region (STN) in the mouse brain 
increases the likelihood that fibers in adjacent areas are recruited by DBS. Comfortingly, our observation that the therapeutic effects of electrical STN DBS in the mouse fall off rapidly below the average current amplitude (200 uA) and vary according to the STN region targeted (Schor and Nelson, 2019) match well with human data and suggest some specificity in the volume of tissue activated (Greenhouse et al., 2011; Tommasi et al., 2008).

For practical reasons, in order to test the physiological and behavioral effects of a wide variety of stimulation parameters (both subtherapeutic and therapeutic), we delivered short (1-minute) epochs of stimulation. These short epochs may not capture the longer term changes in neural activity expected in PD patients, where continuous high frequency stimulation is the current clinical standard. Reducing this concern, many DBS benefits indeed evolve rapidly in PD patients, as in the mouse model (Hristova et al., 2000; Temperli et al., 2003), and our previous work demonstrates consistent behavioral improvement in the model even across longer timescales (Schor and Nelson, 2019).

Excitingly, our observation that non-canonical changes in STN activity confer therapeutic benefit in a mouse model of PD suggests a wider therapeutic space for the treatment of PD. Many therapeutic approaches to PD have been predicated on the idea that inhibition of hyperactive basal ganglia nuclei is required for therapeutic benefit, but our findings, as well as recent work using close-loop DBS (Bouthour et al., 2019; Johnson et al., 2016; Rosin et al., 2011) indicate non-rate-based alterations in activity can improve movement. In addition, our work linking neural activity to behavior in STN DBS for PD may inform the application of DBS to other neuropsychiatric disorders. To rationally apply 
DBS to other conditions, such as addiction or Tourette's syndrome, it is critical to know how electrical stimulation might impact the underlying neural circuitry of disease. We hope that our work may serve as a blueprint for future inquiries into the therapeutic potential of DBS.

\section{Materials and Methods}

\section{Animals}

3-6 month-old wild-type and transgenic C57BI/6 mice of either sex were used in this study.

To allow optical recording and manipulation of glutamatergic STN neurons, homozygous VGlut2-Cre mice (Stock No. 028863, Jackson Labs) were bred to wild-type C57BL/6 mice (Jackson Labs) to yield hemizygous VGlut2-Cre mice. To allow optical recording of GABAergic SNr neurons, homozygous VGAT-Cre mice (Jackson Labs) were bred to wildtype C57BL/6 mice (Jackson Labs) to yield hemizygous VGAT-Cre mice. Animals were housed 1-5 per cage on a 12-hour light/dark cycle with ad libitum access to rodent chow and water. All behavioral manipulations were performed during the light phase. We complied with local and national ethical regulations regarding the use of mice in research. All experimental protocols were approved by the UC San Francisco Institutional Animal Care and Use Committee.

\section{Electrical DBS Devices}

We constructed electrical DBS devices consisting of 3 twisted pairs of stainless steel wire (76.2 micron diameter, coated, AM Systems), cut at an angle to span approximately 300 
microns in DV. These were pressure-fit into female Millmax connectors. Each electrode pair was tested for shorts prior to electrode implantation. For additional details see Schor and Nelson, 2019.

\section{Surgical Procedures}

Stereotaxic surgery was performed between 3 and 6 months of age. Anesthesia was induced with intraperitoneal (IP) injection $(0.1 \mathrm{~mL})$ of ketamine $(40 \mathrm{mg} / \mathrm{kg})$ and xylazine $(10 \mathrm{mg} / \mathrm{kg})$ and maintained with inhaled isoflurane $(0.5 \%-1 \%)$. To model Parkinson's disease in mice, the neurotoxin 6-hydroxydopamine (6-OHDA, $1 \mu \mathrm{L}, 5 \mathrm{mg} / \mathrm{mL}$ ) was injected unilaterally in the left medial forebrain bundle (MFB, -1.0 AP, -1.0 ML, 4.9 DV from Bregma). Desipramine $(0.2 \mathrm{~mL}, 2.5 \mathrm{mg} / \mathrm{mL})$ was injected intraperitoneally (IP) approximately $30 \mathrm{~min}$ prior to 6-OHDA injections to reduce uptake by other monoaminergic neurons in the MFB. Additional surgeries were performed at least two weeks following 6-OHDA injection.

For experiments involving combined electrical STN DBS and optical imaging, a 3-lead bipolar stimulating electrode array was implanted in the ipsilesional STN (-1.8 AP, -1.65 ML, 4.5 DV) (Schor and Nelson, 2019). During the same surgery, VGlut2-Cre mice were injected with Cre-dependent AAV1-Syn-Flex-GCaMP6s-WPRE-SV40 (UPenn, 100 nL injected diluted 1:8 in normal saline, undiluted titer $\left.3.06 \times 10^{13} / \mathrm{mL}\right)$ in the STN $(-1.8$ AP, 1.65 ML, 4.5 DV) and implanted with a photometry fiber-optic ferrule $(0.4 \mathrm{~mm}$, Doric Lenses) above the STN (4.3 DV). VGAT-Cre mice were injected with the same Credependent GCaMP6s vector (300-500 nL injected diluted 1:8 in normal saline) in the SNr 
(-3.2 AP, -1.6 ML, 4.5 DV) and implanted with a fiber-optic ferrule above the SNr (4.3 DV). Wild-type mice were injected with a retrograde virus encoding Cre recombinase [either CAV-Cre (Montpellier, $100 \mathrm{~nL}$ injected undiluted, undiluted titer $1.0 \times 10^{13} / \mathrm{mL}$ ) or AAV2retro-Cre-mCherry (Addgene/UPenn Vector Core, $100 \mathrm{~nL}$ injected undiluted, undiluted titer $\left.7.8 \times 10^{13} / \mathrm{mL}\right)$ ] in the STN (-1.8 AP, -1.65 ML, 4.5 DV) and Cre-dependent GCaMP6s (500 nL injected diluted 1:8 in normal saline) in the primary motor cortex (M1, +2 AP, -1.56 ML, 1 DV) and implanted with a fiber-optic ferrule above M1 (0.8 DV).

For in vivo electrophysiological experiments, mice were implanted with a 16-channel $7 \mathrm{~mm}$ fixed electrode array (Innovative Neurophysiology) in either the STN or the SNr, using the same coordinates as used for GCaMP6s injections above. For combined in vivo electrophysiology/optical stimulation experiments, VGlut2-Cre littermates were injected with Cre-dependent AAV5-DIO-ChR2-eYFP (UPenn, injected diluted 1:2 in normal saline, $100 \mathrm{~nL}$, undiluted titer $1.02 \times 10^{13} / \mathrm{mL}$ ) or AAV5-DIO-eYFP (UNC, injected undiluted, 100 $\mathrm{nL}$, titer $4.4 \times 10^{12} / \mathrm{mL}$ ) in a randomized fashion, and implanted with a 16-channel $7 \mathrm{~mm}$ fixed electrode array (Innovative Neurophysiology) with a fiber-optic ferrule $(0.2 \mathrm{~mm}$, Thor Labs) epoxied $\sim 0.2 \mathrm{~mm}$ above the electrode tips in the STN. For optical stimulation experiments without recording, a fiber-optic ferrule was implanted just above the STN (4.3 DV). A minimum of 3 weeks were allowed for viral expression before behavioral testing.

For experiments involving M1 lesioning, a large rectangular craniectomy was performed to expose brain tissue containing M1 (vertices of rectangle at $[-0.1 \mathrm{AP},-2.1$ $\mathrm{ML}$; [2.6 AP, -2.1 ML]; [2.6 AP, -0.9 ML]; and [-0.1 AP, -0.9 ML]). A micro knife (FST) was then used to carefully remove a $1 \mathrm{~mm}$ thick rectangle of brain tissue that was the height 
and width of the craniectomy under a dissecting microscope. A hemostatic sponge (Ethicon) was used to staunch any bleeding before covering the lesion and adjacent bone with silicone sealant (Kwik-Cast). A 3-lead bipolar stimulating electrode array was then implanted in the ipsilesional STN as previously described. A minimum of 10 days of recovery was allowed before subsequent behavioral testing.

\section{Behavior}

All behavior was conducted in the open field (clear acrylic cylinders, $25 \mathrm{~cm}$ diameter) following 1 day of habituation (20 minutes). Mice were monitored via two cameras, one directly above and one in front of the chamber. Video-tracking software (Noldus Ethovision) or custom-written code (Matlab) was used to quantify locomotor activity, including movement velocity, ipsilateral rotations, and contralateral rotations. Dyskinesia was scored manually by an unblinded rater using a modified version of the abnormal involuntary movement (AIM) scoring method (Cenci and Lundblad, 2007). Dyskinesia was quantified in one-minute increments either every minute (for STN DBS experiments) or every 5 minutes (for levodopa experiments), with axial, limb, and orofacial body segments rated on a scale of 0-3 each. A score of 0 indicates no abnormal movement, while a score of 3 indicates continuous dyskinesia for the one-minute epoch. The scores for each body segment are then summed, with a maximum score of 9 per epoch. 


\section{Pharmacology}

6-OHDA (Sigma Aldrich) was prepared at $5 \mathrm{mg} / \mathrm{mL}$ in normal saline. Levodopa was prepared $(0.5 \mathrm{mg} / \mathrm{mL}$ Sigma Aldrich) with benserazide $(0.25 \mathrm{mg} / \mathrm{mL}$, Sigma Aldrich) in normal saline and always administered at $5 \mathrm{mg} / \mathrm{kg}$.

\section{Electrical Stimulation}

An isolated constant current bipolar stimulator (WPI) was used to deliver electrical stimuli. The timing of stimuli was controlled by TTL input from an Arduino. Electrical stimulation experiments consisted of five 1 min stimulation periods, each preceded and followed by $1 \mathrm{~min}$ of no stimulation, for a total of $11 \mathrm{~min}$. Both the construction of STN DBS electrodes and the determination of optimal stimulation electrode pair were as detailed previously (Schor and Nelson, 2019).

\section{Fiber Photometry}

Fiber photometry signals were acquired through implanted $400 \mu \mathrm{m}$ optical fibers, using an LED driver system (Doric). Following signal modulation, $405 \mathrm{~nm}$ (control signal, from GCaMP autofluorescence) and $465 \mathrm{~nm}$ signals were demodulated via a lock-in amplifier (RZ5P, TDT), visualized, and recorded (Synapse, TDT). Offline, the $405 \mathrm{~nm}$ signal was fit to the $465 \mathrm{~nm}$ signal using a first-degree polynomial fit (Matlab) to extract the noncalcium dependent signal (due to autofluorescence, fiber bending, etc). The fitted $405 \mathrm{~nm}$ signal was then subtracted from the $465 \mathrm{~nm}$ signal to generate a motion-corrected signal. Animals in which the fitted $405 \mathrm{~nm}$ signal did not differ from the $465 \mathrm{~nm}$ signal were 
excluded from further analysis. To remove the gradual, slow bleaching observed in the 〜3 hour saline and levodopa recordings, we additionally fit a double exponential to the $405 \mathrm{~nm}$ signal, linearly fit it to the the motion-corrected signal, and then subtracted it.

Every processed fiber photometry signal was normalized (z-scored) by subtracting the mean and dividing by the standard deviation of the closest preceding "pre" period. For electrical stimulation experiments, the 30 seconds preceding each stimulation period was used to normalize the subsequent 1-min stim and 1-min post period. For levodopa and saline experiments, the 20 minutes prior to injection was used to normalize the subsequent 2.5 hours of signal.

\section{In vivo Electrophysiology}

Single-unit activity from microwires was recorded using a commutated (Doric) multiplexed 96-channel recording system (CerePlex Direct, Blackrock Microsystems). Spike waveforms were filtered at $154-8800 \mathrm{~Hz}$ and digitized at $30 \mathrm{kHz}$. The experimenter manually set a threshold for storage of electrical events. Spike sorting and single units (SUs) were identified offline by manual sorting into clusters (Offline Sorter, Plexon). Waveform features used for separating units were typically a combination of valley amplitude, the first three principal components (PCs), and/or nonlinear energy. Clusters were classified as SUs if they fulfilled the following criteria: $(1)<1 \%$ of spikes occurred within the refractory period and (2) the cluster was statistically different $(p<0.05$, MANOVA using the aforementioned features) from the multi- and other single-unit clusters on the same wire. 


\section{Ex vivo Slice Electrophysiology and Imaging}

To prepare ex vivo slices for whole-cell recordings and GCaMP imaging, mice were deeply anesthetized with IP ketamine-xylazine, transcardially perfused with ice-cold glycerol-based slicing solution, decapitated, and the brain was removed. Glycerol-based slicing solution contained (in mM): 250 glycerol, $2.5 \mathrm{KCl}, 1.2 \mathrm{NaH}_{2} \mathrm{PO}_{4}, 10 \mathrm{HEPES}, 21$ $\mathrm{NaHCO}_{3}, 5$ glucose, $2 \mathrm{MgCl}_{2}, 2 \mathrm{CaCl}_{2}$. The brain was mounted on a submerged chuck, and sequential $275 \mathrm{~mm}$ coronal or sagittal slices were cut on a vibrating microtome (Leica), transferred to a chamber of warm $\left(34^{\circ} \mathrm{C}\right)$ carbogenated ACSF containing (in $\mathrm{mM}$ ) 125 $\mathrm{NaCl}, 26 \mathrm{NaHCO}_{3}, 2.5 \mathrm{KCl}, 1 \mathrm{MgCl}_{2}, 2 \mathrm{CaCl}_{2}, 1.25 \mathrm{NaH}_{2} \mathrm{PO}_{4}, 12.5$ glucose for 30-60 min, then stored in carbogenated ACSF at room temperature. Each slice was then submerged in a chamber superfused with carbogenated $\mathrm{ACSF}$ at $31^{\circ} \mathrm{C}-33^{\circ} \mathrm{C}$ for recordings. STN neurons were targeted using differential interference contrast (DIC) optics in VGlut2-Cre mice on an Olympus BX 51 WIF microscope.

For opsin validation experiments, neurons were patched in the cell-attached configuration using borosilicate glass electrodes (3-5 MOhms) filled with ACSF. Picrotoxin was added to all external solutions for opsin validation. For combined electrophysiologyimaging experiments with GCaMP6s, neurons were patched in the whole-cell currentclamp configuration using borosilicate glass electrodes (3-5 MOhms) filled with potassium methanesulfonate-based internal solution containing (in $\mathrm{mM}$ ): $130 \mathrm{KMeSO}_{3}, 10 \mathrm{NaCl}, 2$ $\mathrm{MgCl}_{2}, 0.16 \mathrm{CaCl}_{2}, 0.5$ EGTA, 10 HEPES, 2 MgATP, 0.3 NaGTP, pH 7.3. All recordings were made using a MultiClamp 700B amplifier (Molecular Devices) and digitized with an ITC-18 A/D board (HEKA). Data were acquired using Igor Pro 6.0 software (Wavemetrics) 
and custom acquisition routines (mafPC, courtesy of M. A. Xu-Friedman). Recordings were filtered at $5 \mathrm{kHz}$ and digitized at $10 \mathrm{kHz}$.

To validate ChR2 function in slice, light pulses were delivered to the slice by a TTLcontrolled LED (Olympus), passed through a GFP (473 nm) filter (Chroma) and the 40X immersion objective. LED intensity was adjusted to yield an output of $3 \mathrm{~mW}$ at the slice. Light was delivered in 1-minute epochs, at $50 \mathrm{~Hz}, 3 \mathrm{~ms}$ pulse width or continuously. Stimulation lasted for $1 \mathrm{~min}$ and was preceded and followed by 30 seconds of recording without stimulation.

For simultaneous electrophysiology and GCaMP6s imaging, current-clamped neurons were stimulated $(0.5-1 \mathrm{nA})$ to elicit action potentials. Stimulation occurred at 10 , $20,40,50$ or 60 , and 100 or $120 \mathrm{~Hz}$ (100 $\mu$ s pulse-width); or was delivered as a long single square wave of constant current for $1 \mathrm{~min}$, preceded and followed by 30 seconds without stimulation. During the duration of each 2 min trial GCaMP fluorescence was either acquired through 1-photon or 2-photon microscopy. 1-photon experiments used a $473 \mathrm{~nm}$ light (TTL-controlled LED, Olympus, paired with GFP filter, Chroma) delivered to the slice at $<1 \mathrm{~mW}$, with GCaMP6s fluorescence captured using an imaging camera attached to the microscope (QI Retiga Electro). For 2-photon microscopy, a 2-photon source (Coherent Ultra II) was tuned to $810 \mathrm{~nm}$ to identify GCaMP expressing neurons and tuned to $940 \mathrm{~nm}$ for calcium imaging. Epi- and transfluorescence signals were captured through a 40×, 0.8 NA objective paired with a 1.4 NA oil immersion condenser (Olympus) to photomultiplier tubes (H10770PA-40 PMTs, Hamamatsu). Data were collected in line scan mode (2-2.4 ms/line, including mirror flyback). 
All ex vivo electrical recordings were passed through a $1 \mathrm{~Hz}$ high-pass filter to remove slow electrical drift and spikes were extracted using the findpeaks function in Matlab. All ex vivo optical recordings were first collapsed into a one-dimensional fluorescence time series by averaging the fluorescence of pixels within a defined regionof-interest. In one-photon recordings, this signal was further processed by fitting a double exponential and subtracting it to remove effects of signal bleaching.

\section{Optogenetic Manipulations}

Prior to optical stimulation experiments, animals were habituated to tethering with custom lightweight patch cables (Precision Fiber Products and ThorLabs) coupled to an optical commutator (Doric Lenses) in the open field for 30 min per day, over 1-2 days. Optical stimulation sessions consisted of five $1 \mathrm{~min}$ stimulation periods, each preceded and followed by $1 \mathrm{~min}$ of no stimulation, for a total of $11 \mathrm{~min}$. TTL-controlled (Master8, A.M.P.I.) blue laser light (488 nm, $3 \mathrm{~mW}$, Shanghai Laser and Optics Century) was delivered in pulse trains $(3 \mathrm{~ms}, 50 \mathrm{~Hz})$ or continuously. Behavior was rated by an observer blinded to the injected construct (ChR2-eYFP or eYFP).

\section{Histology and Microscopy}

Mice were terminally anesthetized with IP ketamine $(200 \mathrm{mg} / \mathrm{kg})$ and xylazine $(40 \mathrm{mg} / \mathrm{kg})$. For mice with an implanted STN DBS device or multielectrode array, the site of stimulation or recording was marked with a solid state, direct current Lesion Maker (Ugo Basile). Mice were then transcardially perfused with $4 \%$ paraformaldyde (PFA), the brain was dissected from the skull and fixed overnight in $4 \%$ PFA, and then was placed in $30 \%$ sucrose at $4^{\circ} \mathrm{C}$ 
for 2-3 days. Brains were then cut into $50 \mu \mathrm{m}$ sagittal sections on a freezing microtome (Leica). To confirm dopamine depletion, tissue was immunostained for tyrosine hydroxylase $(\mathrm{TH})$. Stitched multi-channel fluorescence images were taken on a Nikon 6D conventional widefield microscope at 4-10X, using custom software (UCSF Nikon Imaging Center) to confirm virus expression, fiber placement, and STN DBS placement.

\section{Group Allocation and Blinding}

The order in which each mouse received electrical stimulation during optical recording experiments was randomized daily, as was the type of stimulation administered. Mouse order and stimulation type was also randomized during optogenetic experiments. For optical manipulations, VGluT-Cre positive littermates were randomized to eYFP or ChR2eYFP injection. The experimenter was blinded to experimental group (eYFP vs ChR2eYFP) during behavioral experiments.

\section{Inclusion/Exclusion Criteria}

If the number of ipsilesional $\mathrm{TH}$-positive SNc neurons were $>5 \%$ of the contralateral (unlesioned) side, the animal was excluded from all analyses. Animals that did not show strong virus expression, proper optical fiber placement (within target structure or $<0.2 \mathrm{~mm}$ above), and/or proper STN DBS device placement (within STN) were excluded from further analysis. If DBS leads developed a short, further DBS experiments were terminated, but levodopa experiments were continued. 
A short developed in one mouse in the STN DBS/SNr imaging cohort, such that only levodopa experiments could be performed. We failed to deliver 1 of the 30 DBS parameter combinations in one mouse from the STN DBS/M1 hyperdirect imaging cohort, so no $100 \mathrm{~Hz}$ DBS data were included for this mouse. Across all imaging cohorts, 4 mice were excluded due to insufficient GCaMP expression and/or improper targeting of the optical fiber, resulting in no detectable GCaMP signal on fiber photometry (4 of 30 imaging mice). Across optical stimulation cohorts, 2 mice were excluded due to insufficient eYFP or ChR2-eYFP expression (2 of 22 optical stimulation mice). One mouse in the STN in vivo electrophysiology cohort (1 of 4 ) and one mouse from the $\mathrm{SNr}$ in vivo electrophysiology cohort (1 of 4 ) were excluded due to a lack of clearly isolated single units.

\section{Sample Size Determination, Quantification, Statistical Analysis, and Replication}

For in vivo imaging experiments, no similar studies had been performed by which to estimate effect size. We performed small pilot experiments in each recorded brain region to determine the mean and standard deviation of GCaMP signals in these regions. Effect sizes were estimated from these pilots, or from similarly designed and published electrophysiological studies. The sample size was calculated using 0.90 power to detect a significant difference, two-sided nonparametric comparisons, and alpha of 0.05 . Sample sizes for ex vivo experiments, in vivo electrophysiology, and in vivo optical stimulation were calculated using a similar approach, but based on variance and effect sizes from 
previous experiments conducted in the lab using similar methods as well as published studies from other laboratories.

All data are expressed as mean \pm standard error of the mean (SEM). For all bar graphs for electrical stimulation, optogenetic, and slice experiments, the "stim" or "laser" bar was calculated by averaging all one-minute stimulation periods for each trial. The "pre" and "post" bars were calculated by averaging the 30 seconds before and 30 seconds after each stimulation period, respectively. For all bar graphs involving levodopa or saline, the "LD" or "saline" bar was calculated by averaging the ten minutes between 30-40 min post injection for each trial. The "pre" and "post" bars were calculated by averaging the time period between 15 min and 5 min before injection and between 125 min and 135 min post injection, respectively, for each trial. Correlation between photometry signal and velocity (Supplementary Fig. 5E) was calculated using fit/m in Matlab. Rise time of velocity and calcium signals was calculated as the time it took from the onset of stimulation for the signal to first reach the mean value for that stimulation epoch. Movement starts were defined as events when the mouse's movement velocity changed from less than $0.5 \mathrm{~cm} / \mathrm{s}$ (maintained for at least $1 \mathrm{~s}$ ) to more than $2 \mathrm{~cm} / \mathrm{s}$. Change in photometry signal or firing rate around movement starts (insets in Fig. 6D and Fig. 7F-G) were calculated by subtracting the average fiber signal or firing rate during $1 \mathrm{sec}$ preceding movement start from the average fiber signal or firing rate during $1 \mathrm{sec}$ following movement start.

All data on which a repeated measures one-way ANOVA (rmANOVA) was performed were tested for normality using a Kolmogorov-Smirnov (KS) test. Nonparametric tests (Friedman test, Wilcoxon sign-rank, Wilcoxon rank-sum) were used in all other cases (see 
Supplementary Table 1 for full details). For rmANOVAs and Friedman tests, a Tukey HSD post hoc analysis was applied to correct for multiple comparisons. Data was considered statistically significant for $\mathrm{p}<0.05$.

Multiple cohorts were used in each experiment, and findings were reliably reproduced among all subjects. In vivo optical recordings for each brain region were conducted using at least 3 cohorts of animals. Optogenetic experiments were conducted with 3 cohorts of animals. Electrophysiology experiments were conducted with at least 2 cohorts of animals. M1 lesion experiments were conducted with 2 cohorts of animals. 


\section{Acknowledgements}

The authors would like to acknowledge M. McGregor, P. Starr, J. Ostrem, G. Bouvier, M. Scanziani, and members of the Nelson and Bender Labs for providing advice and feedback on the manuscript. This work was supported by the NINDS (K08 NS081001, ABN; R01, ABN; F31 NS110329, JSS) and the UCSF Discovery Fellows Program (JSS). ABN is the Richard and Shirley Cahill Endowed Chair in Parkinson's Disease Research. 
bioRxiv preprint doi: https://doi.org/10.1101/2021.11.12.468404; this version posted November 13,2021 . The copyright holder for this preprint

(which was not certified by peer review) is the author/funder, who has granted bioRxiv a license to display the preprint in perpetuity. It is made available under aCC-BY-NC-ND 4.0 International license.

\section{Author Contributions}

JSS, ABN, and KJB designed the experiments. JSS, IGM, PWES, ABN, and KJB performed experiments. JSS, RJB, and JAS performed histology. JSS and ABN wrote the manuscript with contributions from all authors. 
bioRxiv preprint doi: https://doi.org/10.1101/2021.11.12.468404; this version posted November 13,2021 . The copyright holder for this preprint (which was not certified by peer review) is the author/funder, who has granted bioRxiv a license to display the preprint in perpetuity. It is made available under aCC-BY-NC-ND 4.0 International license.

\section{Competing Interests}

The authors declare no competing interests. 


\section{REFERENCES}

Andy, O.J., Jurko, M.F., Sias, F.R., 1963. Subthalamotomy in Treatment of Parkinsonian Tremor. J. Neurosurg. 20, 860-870. https://doi.org/10.3171/jns.1963.20.10.0860

Bergman, H., Wichmann, T., DeLong, M.R., 1990. Reversal of experimental parkinsonism by lesions of the subthalamic nucleus. Science 249, 1436-1438. https://doi.org/10.1126/science.2402638

Bouthour, W., Mégevand, P., Donoghue, J., Lüscher, C., Birbaumer, N., Krack, P., 2019. Biomarkers for closed-loop deep brain stimulation in Parkinson disease and beyond. Nat. Rev. Neurol. 15, 343-352. https://doi.org/10.1038/s41582-019-01664

Bové, J., Perier, C., 2012. Neurotoxin-based models of Parkinson's disease. Neuroscience, Neuroscience Disease Models 211, 51-76. https://doi.org/10.1016/j.neuroscience.2011.10.057

Campos, F.L., Carvalho, M.M., Cristovão, A.C., Je, G., Baltazar, G., Salgado, A.J., Kim, Y.-S., Sousa, N., 2013. Rodent models of Parkinson's disease: beyond the motor $\begin{array}{lllll}\text { symptomatology. } & \text { Front. } & \text { Behav. }\end{array}$ https://doi.org/10.3389/fnbeh.2013.00175

Carvalho, M.M., Campos, F.L., Coimbra, B., Pêgo, J.M., Rodrigues, C., Lima, R., Rodrigues, A.J., Sousa, N., Salgado, A.J., 2013. Behavioral characterization of the 6-hydroxidopamine model of Parkinson's disease and pharmacological rescuing of non-motor deficits. Mol. Neurodegener. 8, 14. https://doi.org/10.1186/17501326-8-14

Cenci, M.A., Lundblad, M., 2007. Ratings of L-DOPA-induced dyskinesia in the unilateral 6-OHDA lesion model of Parkinson's disease in rats and mice. Curr. Protoc. Neurosci. Chapter 9, Unit 9.25. https://doi.org/10.1002/0471142301.ns0925s41

Chen, T.-W., Wardill, T.J., Sun, Y., Pulver, S.R., Renninger, S.L., Baohan, A., Schreiter, E.R., Kerr, R.A., Orger, M.B., Jayaraman, V., Looger, L.L., Svoboda, K., Kim, D.S., 2013. Ultra-sensitive fluorescent proteins for imaging neuronal activity. Nature 499, 295-300. https://doi.org/10.1038/nature12354 
Cheruel, F., Dormont, J.F., Farin, D., 1996. Activity of neurons of the subthalamic nucleus in relation to motor performance in the cat. Exp. Brain Res. 108, 206-220. https://doi.org/10.1007/BF00228095

Chiken, S., Nambu, A., 2014. Disrupting neuronal transmission: mechanism of DBS? Front. Syst. Neurosci. 8. https://doi.org/10.3389/fnsys.2014.00033

Chu, H.-Y., Atherton, J.F., Wokosin, D., Surmeier, D.J., Bevan, M.D., 2015. HETEROSYNAPTIC REGULATION OF EXTERNAL GLOBUS PALLIDUS INPUTS TO THE SUBTHALAMIC NUCLEUS BY MOTOR CORTEX. Neuron 85, 364-376. https://doi.org/10.1016/j.neuron.2014.12.022

de Hemptinne, C., Swann, N., Ostrem, J.L., Ryapolova-Webb, E.S., Luciano, M.S., Galifianakis, N., Starr, P.A., 2015. Therapeutic deep brain stimulation reduces cortical phase-amplitude coupling in Parkinson's disease. Nat. Neurosci. 18, 779_ 786. https://doi.org/10.1038/nn.3997

Filali, M., Hutchison, W.D., Palter, V.N., Lozano, A.M., Dostrovsky, J.O., 2004. Stimulation-induced inhibition of neuronal firing in human subthalamic nucleus. Exp. Brain Res. 156, 274-281. https://doi.org/10.1007/s00221-003-1784-y

Gradinaru, V., Mogri, M., Thompson, K.R., Henderson, J.M., Deisseroth, K., 2009. Optical Deconstruction of Parkinsonian Neural Circuitry. Science 324, 354-359. https://doi.org/10.1126/science.1167093

Greenhouse, I., Gould, S., Houser, M., Hicks, G., Gross, J., Aron, A.R., 2011. Stimulation at dorsal and ventral electrode contacts targeted at the subthalamic nucleus has different effects on motor and emotion functions in Parkinson's disease. Neuropsychologia 49 , 528-534. https://doi.org/10.1016/j.neuropsychologia.2010.12.030

Halje, P., Tamtè, M., Richter, U., Mohammed, M., Cenci, M.A., Petersson, P., 2012. Levodopa-Induced Dyskinesia Is Strongly Associated with Resonant Cortical Oscillations. $\quad$ J. Neurosci. $32, \quad$ 16541-16551. https://doi.org/10.1523/JNEUROSCI.3047-12.2012 
Hammond, C., Bergman, H., Brown, P., 2007. Pathological synchronization in Parkinson's disease: networks, models and treatments. Trends Neurosci. 30, 357364. https://doi.org/10.1016/j.tins.2007.05.004

Hashimoto, T., Elder, C.M., Okun, M.S., Patrick, S.K., Vitek, J.L., 2003. Stimulation of the subthalamic nucleus changes the firing pattern of pallidal neurons. J. Neurosci. 23, 1916-1923.

Hickey, P., Stacy, M., 2016. Deep Brain Stimulation: A Paradigm Shifting Approach to $\begin{array}{llll}\text { Treat Parkinson's Disease. } & \text { Front. }\end{array}$ https://doi.org/10.3389/fnins.2016.00173

Hristova, A., Lyons, K., Tröster, A.I., Pahwa, R., Wilkinson, S.B., Koller, W.C., 2000. Effect and Time Course of Deep Brain Stimulation of the Globus Pallidus and Subthalamus on Motor Features of Parkinson's Disease. Clin. Neuropharmacol. 23, 208-211.

Hutchinson, W.D., Levy, R., Dostrovsky, J.O., Lozano, A.M., Lang, A.E., 1997. Effects of apomorphine on globus pallidus neurons in parkinsonian patients. Ann. Neurol. 42, 767-775. https://doi.org/10.1002/ana.410420513

Johnson, L.A., Nebeck, S.D., Muralidharan, A., Johnson, M.D., Baker, K.B., Vitek, J.L., 2016. Closed-loop deep brain stimulation effects on parkinsonian motor symptoms in a non-human primate -- is beta enough? Brain Stimulat. 9, 892-896. https://doi.org/10.1016/j.brs.2016.06.051

Johnson, L.A., Wang, J., Nebeck, S.D., Zhang, J., Johnson, M.D., Vitek, J.L., 2020. Direct Activation of Primary Motor Cortex during Subthalamic But Not Pallidal Deep Brain $\begin{array}{llll}\text { Stimulation. } \quad \text { J. Neurosci. } & \text { 2166-2177. }\end{array}$ https://doi.org/10.1523/JNEUROSCI.2480-19.2020

Kawai, R., Markman, T., Poddar, R., Ko, R., Fantana, A., Dhawale, A., Kampff, A.R., Ölveczky, B.P., 2015. Motor cortex is required for learning but not executing a motor skill. Neuron 86, 800-812. https://doi.org/10.1016/j.neuron.2015.03.024

Kita, H., Kitai, S.T., 1987. Efferent projections of the subthalamic nucleus in the rat: light and electron microscopic analysis with the PHA-L method. J. Comp. Neurol. 260, 435-452. https://doi.org/10.1002/cne.902600309 
Kita, T., Kita, H., 2012. The Subthalamic Nucleus Is One of Multiple Innervation Sites for Long-Range Corticofugal Axons: A Single-Axon Tracing Study in the Rat. J. Neurosci. 32, 5990-5999. https://doi.org/10.1523/JNEUROSCI.5717-11.2012

Kovaleski, R.F., Callahan, J.W., Chazalon, M., Wokosin, D.L., Baufreton, J., Bevan, M.D., 2020. Dysregulation of external globus pallidus-subthalamic nucleus network dynamics in parkinsonian mice during cortical slow-wave activity and activation. J. Physiol. 598, 1897-1927. https://doi.org/10.1113/JP279232

Kühn, A.A., Kempf, F., Brücke, C., Gaynor Doyle, L., Martinez-Torres, I., Pogosyan, A., Trottenberg, T., Kupsch, A., Schneider, G.-H., Hariz, M.I., Vandenberghe, W., Nuttin, B., Brown, P., 2008. High-frequency stimulation of the subthalamic nucleus suppresses oscillatory beta activity in patients with Parkinson's disease in parallel with improvement in motor performance. J. Neurosci. Off. J. Soc. Neurosci. 28, 6165-6173. https://doi.org/10.1523/JNEUROSCI.0282-08.2008

Levy, R., Dostrovsky, J.O., Lang, A.E., Sime, E., Hutchison, W.D., Lozano, A.M., 2001. Effects of apomorphine on subthalamic nucleus and globus pallidus internus neurons in patients with Parkinson's disease. J. Neurophysiol. 86, 249-260. https://doi.org/10.1152/jn.2001.86.1.249

Li, Q., Ke, Y., Chan, D.C.W., Qian, Z.-M., Yung, K.K.L., Ko, H., Arbuthnott, G.W., Yung, W.-H., 2012. Therapeutic Deep Brain Stimulation in Parkinsonian Rats Directly Influences Motor Cortex. Neuron 76, 1030-1041. https://doi.org/10.1016/j.neuron.2012.09.032

Little, S., Brown, P., 2014. The functional role of beta oscillations in Parkinson's disease. Parkinsonism Relat. Disord. 20 Suppl 1, S44-48. https://doi.org/10.1016/S13538020(13)70013-0

Liu, D., Li, W., Ma, C., Zheng, W., Yao, Y., Tso, C.F., Zhong, P., Chen, X., Song, J.H., Choi, W., Paik, S.-B., Han, H., Dan, Y., 2020. A common hub for sleep and motor control in the substantia nigra. Science 367, 440-445. https://doi.org/10.1126/science.aaz0956 
Lozano, A.M., Lang, A.E., Levy, R., Hutchison, W., Dostrovsky, J., 2000. Neuronal recordings in Parkinson's disease patients with dyskinesias induced by apomorphine. Ann. Neurol. 47, S141-146.

Markowitz, J.E., Gillis, W.F., Beron, C.C., Neufeld, S.Q., Robertson, K., Bhagat, N.D., Peterson, R.E., Peterson, E., Hyun, M., Linderman, S.W., Sabatini, B.L., Datta, S.R., 2018. The Striatum Organizes 3D Behavior via Moment-to-Moment Action Selection. Cell 174, 44-58.e17. https://doi.org/10.1016/j.cell.2018.04.019

McIntyre, C.C., Grill, W.M., 1999. Excitation of central nervous system neurons by nonuniform electric fields. Biophys. J. 76, 878-888.

McIntyre, C.C., Grill, W.M., Sherman, D.L., Thakor, N.V., 2004. Cellular Effects of Deep Brain Stimulation: Model-Based Analysis of Activation and Inhibition. J. Neurophysiol. 91, 1457-1469. https://doi.org/10.1152/jn.00989.2003

Miocinovic, S., Hemptinne, C. de, Chen, W., Isbaine, F., Willie, J.T., Ostrem, J.L., Starr, P.A., 2018. Cortical potentials evoked by subthalamic stimulation demonstrate a short latency hyperdirect pathway in humans. J. Neurosci. 1327-18. https://doi.org/10.1523/JNEUROSCI.1327-18.2018

Moran, A., Stein, E., Tischler, H., Bar-Gad, I., 2012. Decoupling neuronal oscillations during subthalamic nucleus stimulation in the parkinsonian primate. Neurobiol. Dis., Assessment of Gene Expression in Neuropsychiatric Disease 45, 583-590. https://doi.org/10.1016/j.nbd.2011.09.016

Moran, A., Stein, E., Tischler, H., Belelovsky, K., Bar-Gad, I., 2011. Dynamic Stereotypic Responses of Basal Ganglia Neurons to Subthalamic Nucleus High-Frequency Stimulation in the Parkinsonian Primate. Front. Syst. Neurosci. 5. https://doi.org/10.3389/fnsys.2011.00021

Nowak, L.G., Bullier, J., 1998. Axons, but not cell bodies, are activated by electrical stimulation in cortical gray matter. II. Evidence from selective inactivation of cell bodies and axon initial segments. Exp. Brain Res. 118, 489-500. https://doi.org/10.1007/s002210050305

Pan, M.-K., Kuo, S.-H., Tai, C.-H., Liou, J.-Y., Pei, J.-C., Chang, C.-Y., Wang, Y.-M., Liu, W.-C., Wang, T.-R., Lai, W.-S., Kuo, C.-C., 2016. Neuronal firing patterns outweigh 
circuitry oscillations in parkinsonian motor control. J. Clin. Invest. 126, 4516-4526. https://doi.org/10.1172/JCl88170

Papa, S.M., Desimone, R., Fiorani, M., Oldfield, E.H., 1999. Internal globus pallidus discharge is nearly suppressed during levodopa-induced dyskinesias. Ann. Neurol. 46, 732-738.

Polyakova, Z., Chiken, S., Hatanaka, N., Nambu, A., 2020. Cortical Control of Subthalamic Neuronal Activity through the Hyperdirect and Indirect Pathways in Monkeys. J. Neurosci. 40, 7451-7463. https://doi.org/10.1523/JNEUROSCI.077220.2020

Reese, R., Leblois, A., Steigerwald, F., Pötter-Nerger, M., Herzog, J., Mehdorn, H.M., Deuschl, G., Meissner, W.G., Volkmann, J., 2011. Subthalamic deep brain stimulation increases pallidal firing rate and regularity. Exp. Neurol. 229, 517-521. https://doi.org/10.1016/j.expneurol.2011.01.020

Rosin, B., Slovik, M., Mitelman, R., Rivlin-Etzion, M., Haber, S.N., Israel, Z., Vaadia, E., Bergman, H., 2011. Closed-loop deep brain stimulation is superior in ameliorating parkinsonism. Neuron 72, 370-384. https://doi.org/10.1016/j.neuron.2011.08.023

Sabatini, B.L., 2019. The impact of reporter kinetics on the interpretation of data gathered with fluorescent reporters. bioRxiv 834895. https://doi.org/10.1101/834895

Sanders, T.H., Jaeger, D., 2016. Optogenetic stimulation of cortico-subthalamic projections is sufficient to ameliorate bradykinesia in 6-ohda lesioned mice. Neurobiol. Dis. 95, 225-237. https://doi.org/10.1016/j.nbd.2016.07.021

Schor, J.S., Nelson, A.B., 2019. Multiple stimulation parameters influence efficacy of deep brain stimulation in parkinsonian mice. J. Clin. Invest. 129, 3833-3838. https://doi.org/10.1172/JCl122390

Shimamoto, S.A., Ryapolova-Webb, E.S., Ostrem, J.L., Galifianakis, N.B., Miller, K.J., Starr, P.A., 2013. Subthalamic nucleus neurons are synchronized to primary motor cortex local field potentials in Parkinson's disease. J. Neurosci. Off. J. Soc. Neurosci. 33, 7220-7233. https://doi.org/10.1523/JNEUROSCI.4676-12.2013 
Smith, Y., Parent, A., 1988. Neurons of the subthalamic nucleus in primates display glutamate but not GABA immunoreactivity. Brain Res. 453, 353-356. https://doi.org/10.1016/0006-8993(88)90177-1

Stein, E., Bar-Gad, I., 2013. Beta oscillations in the cortico-basal ganglia loop during parkinsonism. Exp. Neurol., Special Issue: Neuronal oscillations in movement disorders 245, 52-59. https://doi.org/10.1016/j.expneurol.2012.07.023

Temperli, P., Ghika, J., Villemure, J.-G., Burkhard, P.R., Bogousslavsky, J., Vingerhoets, F.J.G., 2003. How do parkinsonian signs return after discontinuation of subthalamic DBS? Neurology 60, 78-81. https://doi.org/10.1212/WNL.60.1.78

Tommasi, G., Krack, P., Fraix, V., Bas, J.-F.L., Chabardes, S., Benabid, A.-L., Pollak, P., 2008. Pyramidal tract side effects induced by deep brain stimulation of the subthalamic nucleus. J. Neurol. Neurosurg. Psychiatry 79, 813-819. https://doi.org/10.1136/jnnp.2007.117507

Trevathan, J.K., Asp, A.J., Nicolai, E.N., Trevathan, J., Kremer, N.A., Kozai, T.D.Y., Cheng, D., Schachter, M., Nassi, J.J., Otte, S.L., Parker, J.G., Lujan, J.L., Ludwig, K., 2020. Calcium imaging in freely-moving mice during electrical stimulation of deep brain structures. J. Neural Eng. https://doi.org/10.1088/1741-2552/abb7a4

Ungerstedt, U., 1968. 6-hydroxy-dopamine induced degeneration of central monoamine neurons. Eur. J. Pharmacol. 5, 107-110. https://doi.org/10.1016/00142999(68)90164-7

Walaas, I., Fonnum, F., 1979. The distribution and origin of glutamate decarboxylase and choline acetyltransferase in ventral pallidum and other basal forebrain regions. Brain Res. 177, 325-336. https://doi.org/10.1016/0006-8993(79)90783-2

Wichmann, T., 2019. Changing views of the pathophysiology of Parkinsonism. Mov. Disord. Off. J. Mov. Disord. Soc. 34, 1130-1143. https://doi.org/10.1002/mds.27741

Wichmann, T., Bergman, H., DeLong, M.R., 1994. The primate subthalamic nucleus. I. Functional properties in intact animals. J. Neurophysiol. 72, 494-506. https://doi.org/10.1152/jn.1994.72.2.494 
Wingeier, B., Tcheng, T., Koop, M.M., Hill, B.C., Heit, G., Bronte-Stewart, H.M., 2006. Intra-operative STN DBS attenuates the prominent beta rhythm in the STN in Parkinson's disease. Exp. Neurol. 197, 244-251. https://doi.org/10.1016/j.expneurol.2005.09.016

Yoon, H.H., Park, J.H., Kim, Y.H., Min, J., Hwang, E., Lee, C.J., Suh, J.-K.F., Hwang, O., Jeon, S.R., 2014. Optogenetic inactivation of the subthalamic nucleus improves forelimb akinesia in a rat model of Parkinson disease. Neurosurgery 74, 533-540; discussion 540-541. https://doi.org/10.1227/NEU.0000000000000297

Yu, C., Cassar, I.R., Sambangi, J., Grill, W.M., 2020. Frequency-Specific Optogenetic Deep Brain Stimulation of Subthalamic Nucleus Improves Parkinsonian Motor Behaviors. J.

Neurosci.

40 , 4323-4334. https://doi.org/10.1523/JNEUROSCI.3071-19.2020

Zhuang, Q.-X., Li, G.-Y., Li, B., Zhang, C.-Z., Zhang, X.-Y., Xi, K., Li, H.-Z., Wang, J.-J., Zhu, J.-N., 2018. Regularizing firing patterns of rat subthalamic neurons ameliorates parkinsonian motor deficits. J. Clin. Invest. 128, 5413-5427. https://doi.org/10.1172/JCI99986

Zimnik, A.J., Nora, G.J., Desmurget, M., Turner, R.S., 2015. Movement-Related Discharge in the Macaque Globus Pallidus during High-Frequency Stimulation of the Subthalamic Nucleus. J. Neurosci. 35, 3978-3989. https://doi.org/10.1523/JNEUROSCI.4899-14.2015 


\section{Figures}
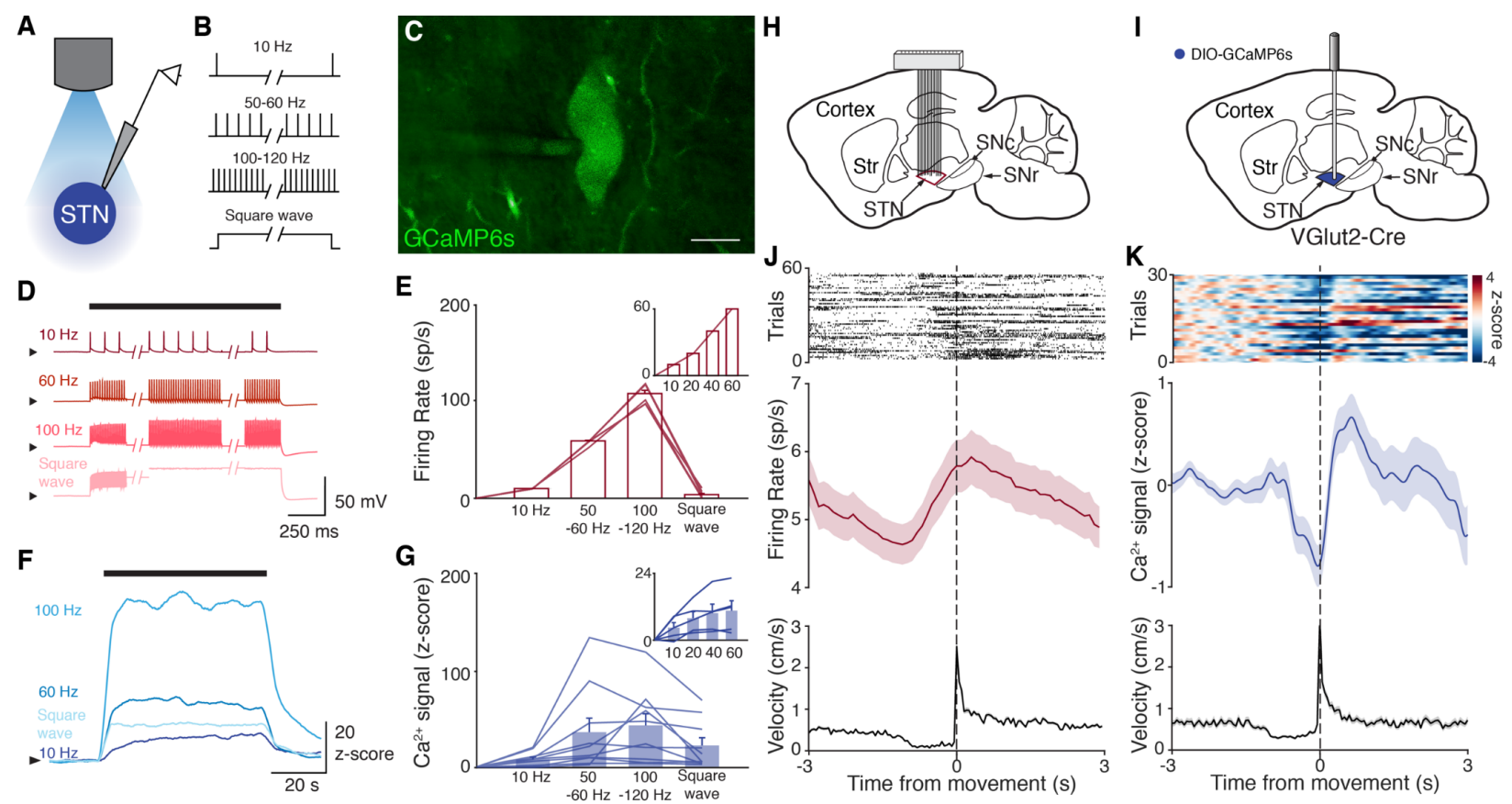

Figure 1. STN GCaMP signals correlate with spiking measured by

electrophysiology. (A-G) Combined ex vivo electrophysiological and calcium imaging recordings in STN neurons. Neurons were patched in the whole-cell current-clamp configuration. (A) Recording configuration. (B) Schematic showing current-clamp stimulation protocol. (C) Image of GCaMP-expressing STN neuron (scale bar=10 $\mu \mathrm{m}$ ). (D) Representative STN neuron responses to the indicated current-clamp stimulation. (E) Average firing rate of STN neurons in response to stimulation ( $n=10$ cells, $N=3$ mice for main; $n=5$ cells, $N=1$ mouse for inset). (F) Representative trace of $z$-scored STN GCaMP signal in response to current-clamp stimulation. (G) Average z-scored STN GCaMP signal in response to current-clamp stimulation ( $n=10$ cells, $N=3$ mice for main; $n=5$ cells, $N=1$ mouse for inset). Arrowhead in current-clamp traces and GCaMP traces corresponds to $-75 \mathrm{mV}$ and $0 \mathrm{z}$-score, respectively. Bar plots show mean \pm SEM. $(\mathrm{H}-\mathrm{K})$ In vivo 
electrophysiological and calcium imaging recordings in STN neurons from freely moving parkinsonian mice, aligned to movement starts. (H) Sagittal schematic showing multielectrode array implant in the STN for single-unit electrophysiology. (I) Sagittal schematic showing STN GCaMP and fiber implant for photometry. (J) Representative STN single-unit firing (top), average firing rate (middle), and average velocity (bottom) aligned to movement starts ( $\mathrm{n}=17$ cells, $N=3$ mice). (K) Representative STN fiber photometry signal (top), average fiber photometry signal (middle), and average velocity (bottom) aligned to movement starts ( $\mathrm{N}=8$ mice). Average firing rate, photometry, and velocity traces show mean \pm SEM. 
A

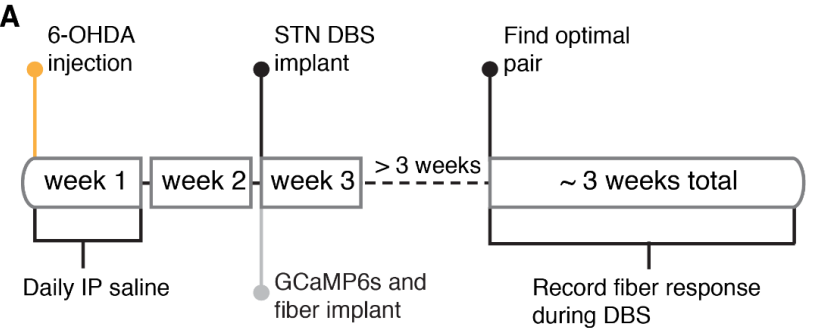

C $60 \mathrm{~Hz}$ DBS

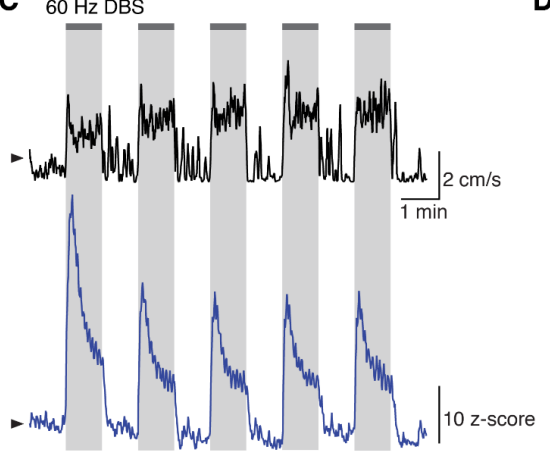

G

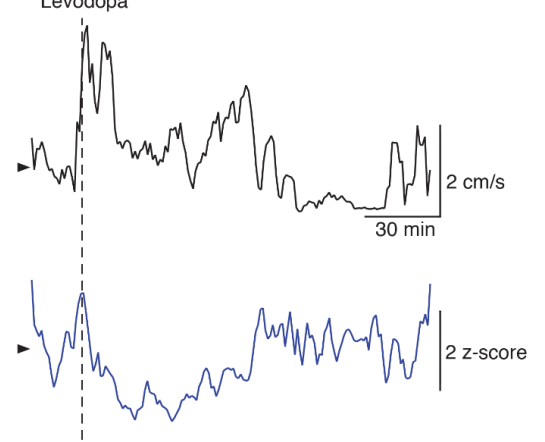

D

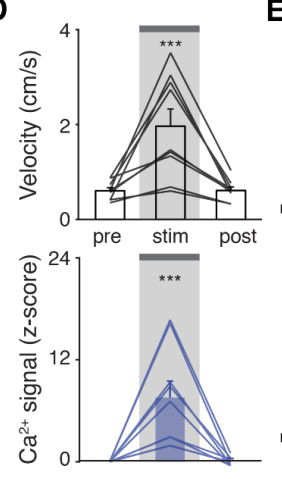

H

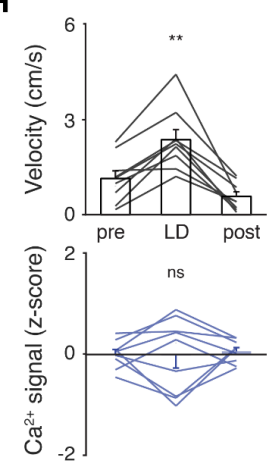

B

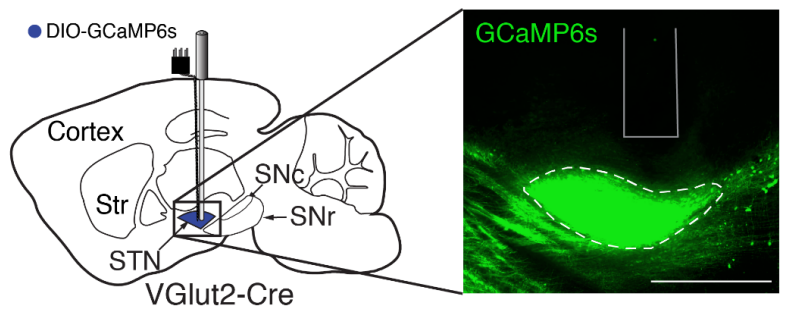

E $100 \mathrm{~Hz}$ DBS

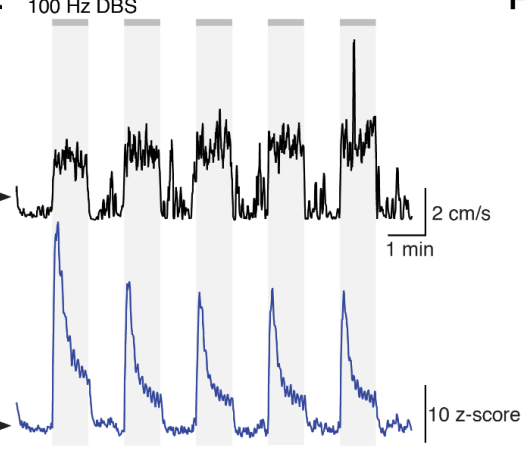

I Levodopa

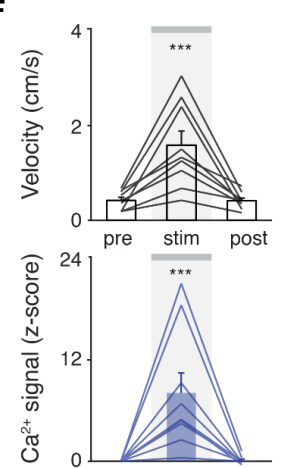

J
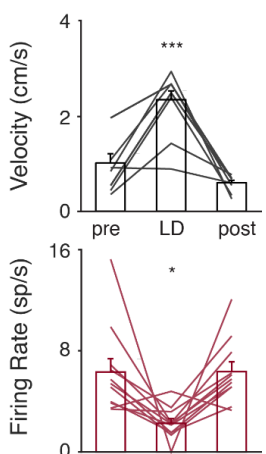

Figure 2. STN DBS consistently increases STN activity. (A) Experimental timeline. (B)

Left: Sagittal schematic showing STN DBS and GCaMP fiber photometry. Right:

Postmortem sagittal section showing GCaMP expression and estimated fiber placement

in the STN (inset, scale=500 $\mu \mathrm{m}$ ). (C) Representative single-session velocity (black) and

STN GCaMP signal (blue) in response to $60 \mathrm{~Hz}$ STN DBS. (D) Average velocity (top) and

STN GCaMP signal (bottom) before, during, and after $60 \mathrm{~Hz}$ STN DBS (N=9 mice).

Representative single-session velocity (black) and STN GCaMP signal (blue) in response

to $100 \mathrm{~Hz}$ STN DBS. (F) Average velocity (top) and STN GCaMP signal (bottom) before, during, and after $100 \mathrm{~Hz}$ STN DBS (N=9 mice). (G) Representative single-session velocity 
(black) and STN GCaMP signal (blue) before and after levodopa injection (dotted line).

(H) Average velocity (top) and STN GCaMP signal (bottom) before, during, and after levodopa treatment ( $\mathrm{N}=9$ mice). (I) Representative single-session velocity (black) and STN single-unit activity (red) before and after levodopa injection (dotted line). (J) Average velocity (top) and STN single-unit activity (bottom) before, during, and after levodopa treatment ( $n=11$ cells, $N=3$ mice). Statistical significance was determined using a oneway repeated measures ANOVA with a Tukey HSD post hoc analysis applied to correct for multiple comparisons; ${ }^{*} P<0.05,{ }^{* *} P<0.01,{ }^{* * *} P<0.001$ (only comparison between pre and stim/LD shown, see Supplementary Table 1 for detailed statistics). Arrowhead in velocity, GCaMP, and single-unit electrophysiology traces corresponds to $1 \mathrm{~cm} / \mathrm{s}, 0 \mathrm{z}$ score, and $0 \mathrm{sp} / \mathrm{s}$, respectively. Bar plots show mean \pm SEM. 
bioRxiv preprint doi: https://doi.org/10.1101/2021.11.12.468404; this version posted November 13,2021 . The copyright holder for this preprint (which was not certified by peer review) is the author/funder, who has granted bioRxiv a license to display the preprint in perpetuity. It is made available under aCC-BY-NC-ND 4.0 International license.

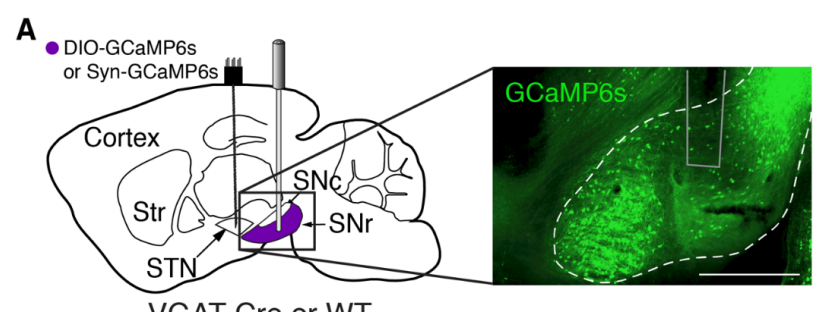

B $60 \mathrm{~Hz}$ DBS

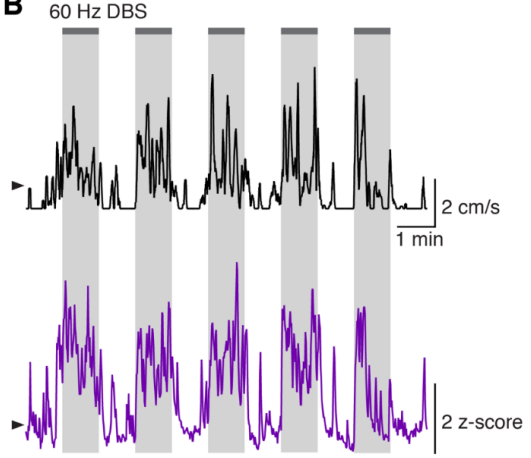

D $100 \mathrm{~Hz}$ DBS
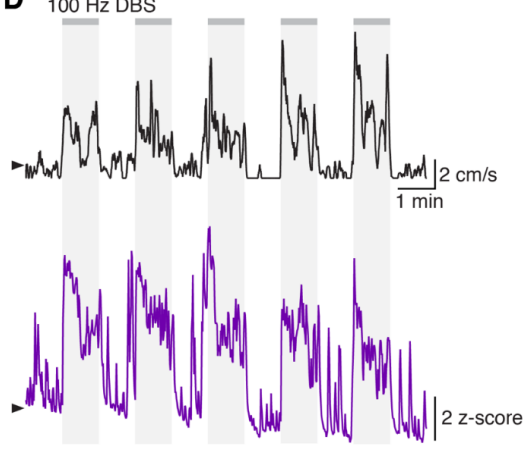

F

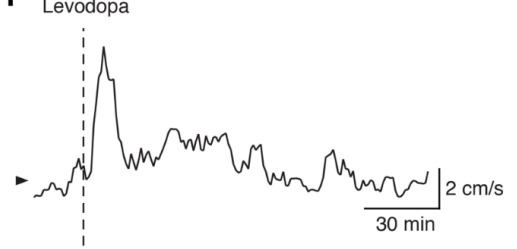

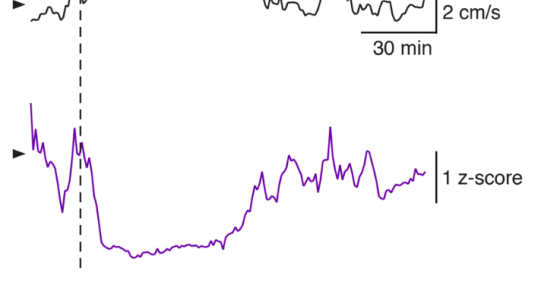

H

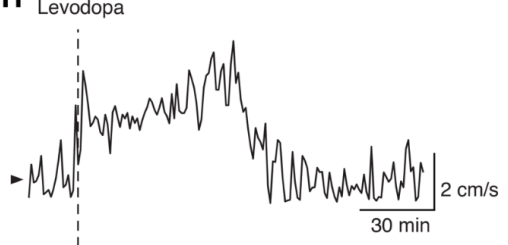

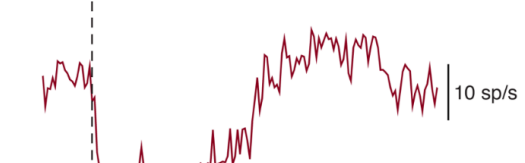

C

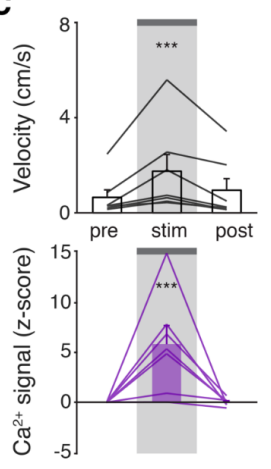

E
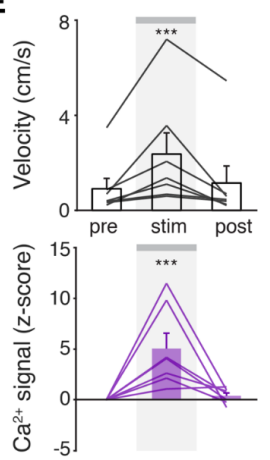

G
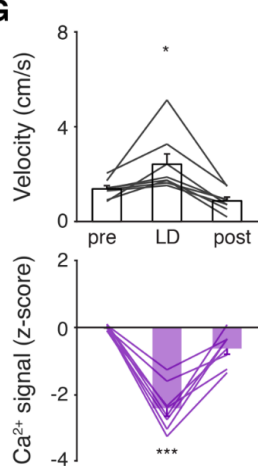

I

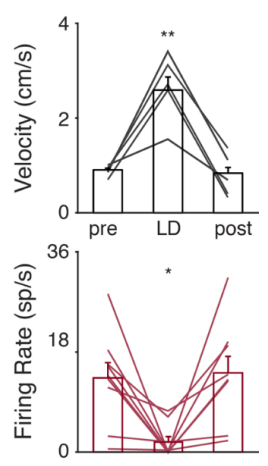


Figure 3. STN DBS increases basal ganglia output. (A) Left: Sagittal schematic showing STN DBS and SNr GCaMP fiber photometry. Right: Postmortem sagittal section showing GCaMP expression and estimated fiber placement in the $\mathrm{SNr}$ (inset, scale=500 $\mu \mathrm{m})$. (B) Representative single-session velocity (black) and SNr GCaMP signal (purple) in response to $60 \mathrm{~Hz}$ STN DBS. (C) Average velocity (top) and SNr GCaMP signal (bottom) before, during, and after $60 \mathrm{~Hz}$ STN DBS ( $\mathrm{N}=7$ mice). (D) Representative single-session velocity (black) and SNr GCaMP signal (purple) in response to $100 \mathrm{~Hz}$ STN DBS. (E) Average velocity (top) and SNr GCaMP signal (bottom) before, during, and after $100 \mathrm{~Hz}$ STN DBS ( $N=7$ mice). (F) Representative single-session velocity (black) and SNr GCaMP signal (purple) before and after levodopa injection (dotted line). (G) Average velocity (top) and SNr GCaMP signal (bottom) before, during, and after levodopa treatment ( $\mathrm{N}=8$ mice). (H) Representative single-session velocity (black) and SNr single-unit activity (red) before and after levodopa injection (dotted line). (I) Average velocity (top) and SNr single-unit activity (bottom) before, during, and after levodopa treatment ( $\mathrm{n}=9$ cells, $\mathrm{N}=3$ mice). Statistical significance was determined using a one-way repeated measures ANOVA with a Tukey HSD post hoc analysis applied to correct for multiple comparisons; ${ }^{*} P<0.05$, ${ }^{* *} P<0.01,{ }^{* * *} P<0.001$ (only comparison between pre and stim/LD shown, see Supplementary Table 1 for detailed statistics). Arrowhead in velocity, GCaMP, and singleunit electrophysiology traces corresponds to $1 \mathrm{~cm} / \mathrm{s}, 0 \mathrm{z}$-score, and $0 \mathrm{sp} / \mathrm{s}$, respectively. Bar plots show mean \pm SEM. 


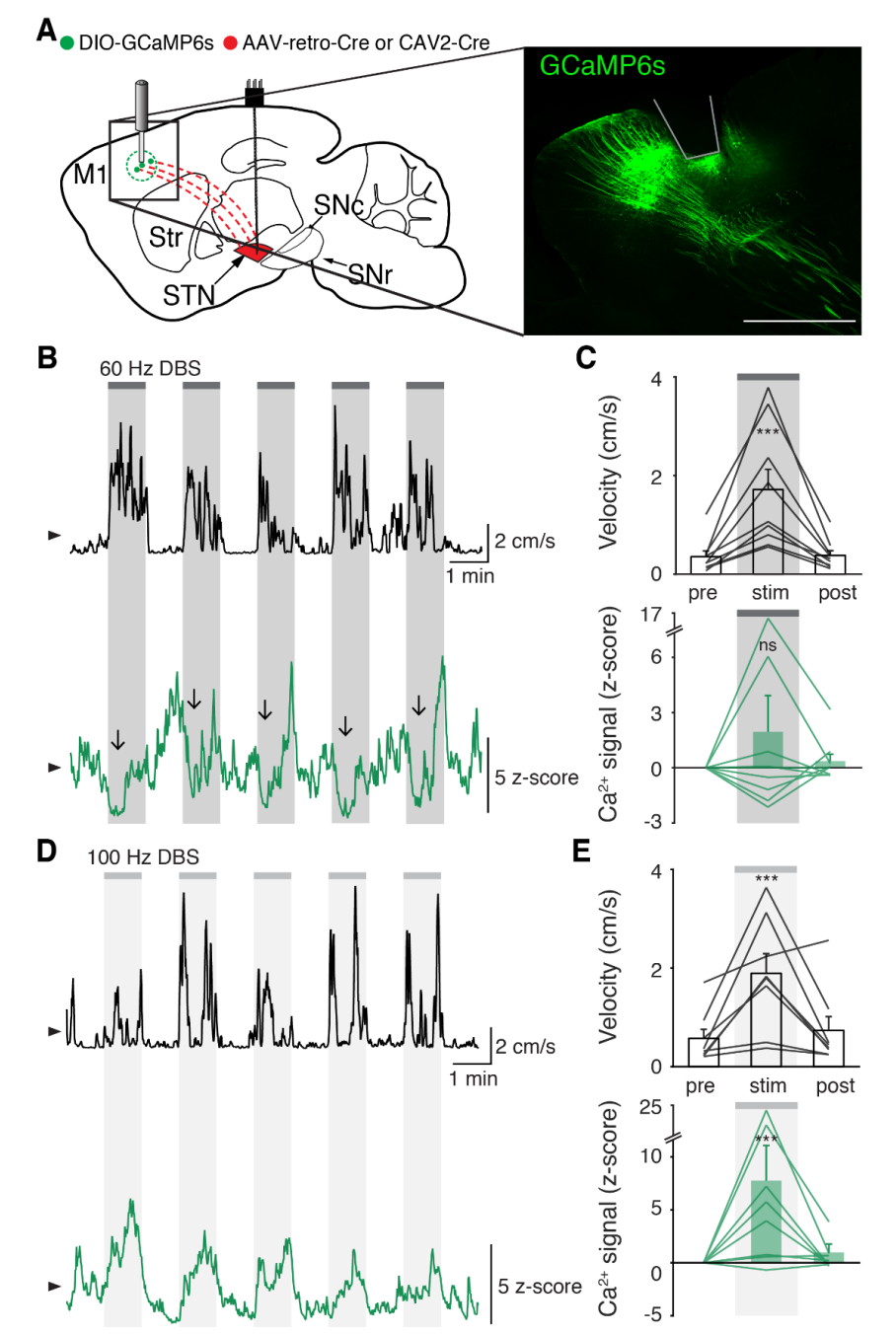

Figure 4. STN DBS variably changes hyperdirect M1 neural activity. (A) Left: Sagittal schematic showing STN DBS and M1-STN GCaMP fiber photometry. Right: Postmortem sagittal section showing GCaMP expression and estimated fiber placement in M1 (inset, scale $=500 \mu \mathrm{m}$ ). (B) Representative single-session velocity (black) and M1-STN GCaMP signal (green) in response to $60 \mathrm{~Hz}$ STN DBS. (C) Average velocity (top) and M1-STN GCaMP signal (bottom) before, during, and after $60 \mathrm{~Hz}$ STN DBS ( $\mathrm{N}=9$ mice). (D) Representative single-session velocity (black) and M1-STN GCaMP signal (green) in response to $100 \mathrm{~Hz}$ STN DBS. (E) Average velocity (top) and M1-STN GCaMP signal (bottom) before, during, and after $100 \mathrm{~Hz}$ STN DBS ( $\mathrm{N}=8$ mice). Statistical significance 
bioRxiv preprint doi: https://doi.org/10.1101/2021.11.12.468404; this version posted November 13,2021 . The copyright holder for this preprint

(which was not certified by peer review) is the author/funder, who has granted bioRxiv a license to display the preprint in perpetuity. It is made available under aCC-BY-NC-ND 4.0 International license.

was determined using a one-way repeated measures ANOVA with a Tukey HSD post hoc analysis applied to correct for multiple comparisons; ${ }^{* * *} P<0.001$ (only comparison between pre and stim shown, see Supplementary Table 1 for detailed statistics). Arrowhead in velocity and GCaMP traces corresponds to $1 \mathrm{~cm} / \mathrm{s}$ and 0 z-score, respectively. Bar plots show mean \pm SEM. 


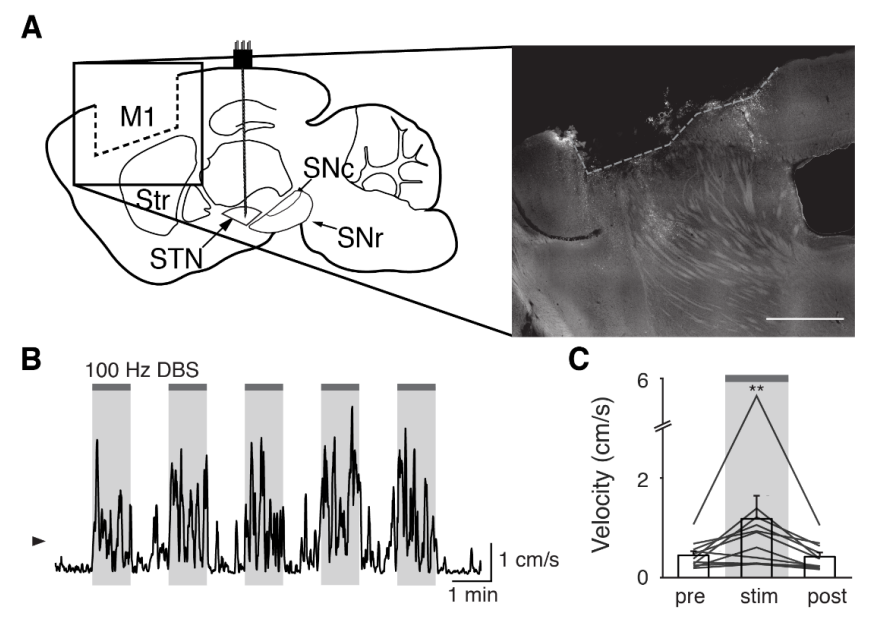

Figure 5. Surgical removal of M1 does not abolish therapeutic benefit of STN DBS.

(A) Left: Sagittal schematic showing STN DBS and M1 surgical lesion. Right: Postmortem sagittal section showing estimated extent of M1 lesion (inset, scale $=500 \mu \mathrm{m}$ ). (B)

Representative single-session velocity of an M1-lesioned hemiparkinsonian mouse in response to $100 \mathrm{~Hz}$ STN DBS. (C) Average velocity before, during, and after $100 \mathrm{~Hz}$ STN DBS in $\mathrm{M} 1$-lesioned hemiparkinsonian mice $(\mathrm{N}=11$ mice). Statistical significance was determined using a one-way repeated measures ANOVA with a Tukey HSD post hoc analysis applied to correct for multiple comparisons; ${ }^{* *} P<0.01$ (only comparison between pre and stim shown, see Supplementary Table 1 for detailed statistics). Arrowhead in velocity trace corresponds to $1 \mathrm{~cm} / \mathrm{s}$. Bar plots show mean \pm SEM. 

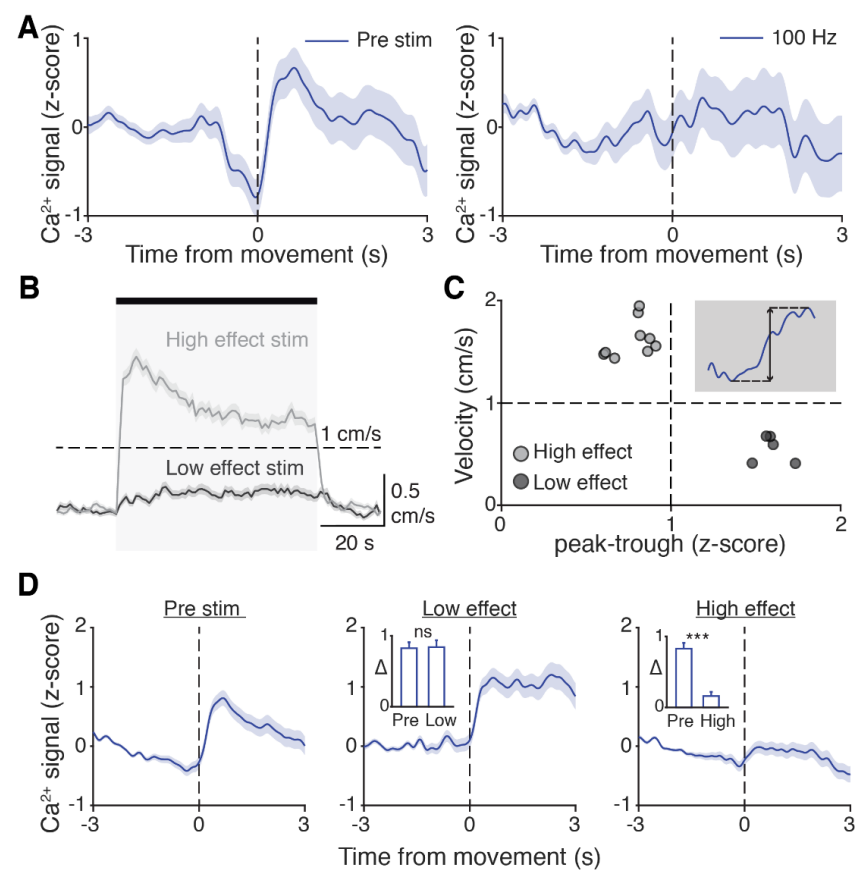

Figure 6. STN movement-related activity is disrupted by therapeutic STN DBS. (A)

Average STN fiber photometry signal aligned to movement starts during pre-stim periods (left) and during $100 \mathrm{~Hz}$ STN DBS stimulation (right). (B) Average movement velocity over time during high effect stimulation (light grey, achieves average velocity $>1 \mathrm{~cm} / \mathrm{s}$ ) and low effect stimulation (dark grey, achieves average velocity $<1 \mathrm{~cm} / \mathrm{s}$ ). (C) Scatter plot comparing peak-trough distance in the average movement-aligned photometry trace (inset) to velocity during high effect (light grey) and low effect (dark grey) stimulation parameters. Each dot represents an average across all mice for each stimulation parameter ( $\mathrm{N}=8$ mice). (D) Average STN fiber photometry signal aligned to movement starts during pre-stim periods (left) and during low effect STN DBS stimulation (middle) and high effect STN DBS stimulation (right). Inset bar graphs show difference between average fiber signal in $1 \mathrm{sec}$ following movement start and $1 \mathrm{sec}$ preceding movement start (see Methods for further details) during pre, low effect, or high effect stim. Statistical 
bioRxiv preprint doi: https://doi.org/10.1101/2021.11.12.468404; this version posted November 13,2021 . The copyright holder for this preprint (which was not certified by peer review) is the author/funder, who has granted bioRxiv a license to display the preprint in perpetuity. It is made available under aCC-BY-NC-ND 4.0 International license.

significance was determined using a Wilcoxon rank-sum test; ${ }^{* * *} P<0.001$ (see Supplementary Table 1 for detailed statistics). Bar plots, photometry, and velocity traces show mean \pm SEM. 


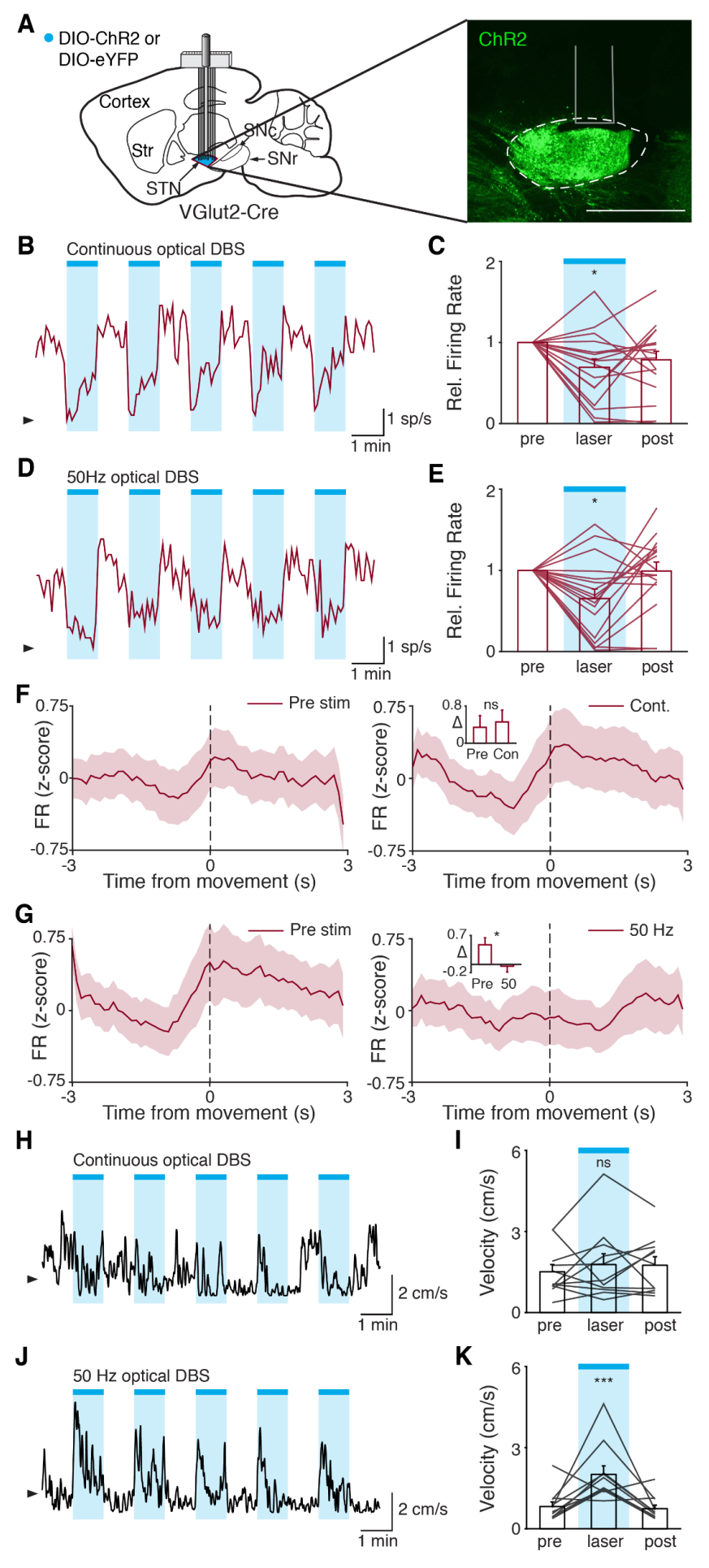

Figure 7. Disruption of STN dynamics is sufficient to provide therapeutic benefit.

(A) Left: Sagittal schematic showing viral injection and 16-channel optrode implantation in the STN. Right: Postmortem sagittal section showing ChR2 expression in the STN 
(inset, scale $=500 \mu \mathrm{m}$ ). (B) Representative STN single-unit firing in response to continuous optical stimulation, given in 1-minute epochs (blue bars). (C) Average zscored firing rate of STN single units before, during, and after continuous optical stimulation ( $\mathrm{n}=17$ neurons, $\mathrm{N}=3$ mice). (D) Representative STN single-unit firing in response to $50 \mathrm{~Hz}$ optical stimulation, given in 1-minute epochs (blue bars). (E) Average z-scored firing rate of STN single units before, during, and after $50 \mathrm{~Hz}$ optical stimulation ( $n=17$ neurons, $N=3$ mice). (F) Average z-scored firing rate of STN single units aligned to movement starts before (left) and during (right) continuous optical stimulation. Inset: average change in firing rate around movement starts (see Methods for further details) before (pre) or during (con) constant optical stimulation ( $\mathrm{n}=17$ neurons, $N=3$ mice). (G) Average z-scored firing rate of STN single units aligned to movement starts before (left) and during (right) $50 \mathrm{~Hz}$ optical stimulation. Inset: average change in firing rate around movement starts before (pre) and during (50) $50 \mathrm{~Hz}$ optical stim ( $\mathrm{n}=17$ neurons, $N=3$ mice). (H) Representative single-session movement velocity in response to continuous optical stimulation, given in 1-minute epochs. (I) Average velocity before, during, and after continuous optical stimulation ( $\mathrm{N}=11$ mice). (J) Representative single-session movement velocity in response to $50 \mathrm{~Hz}$ optical stimulation, given in 1-minute epochs. (K) Average velocity before, during, and after $50 \mathrm{~Hz}$ optical stimulation ( $\mathrm{N}=11$ mice). Statistical significance was determined using a Wilcoxon rank-sum test (F-G) or a one-way repeated measures ANOVA with a Tukey HSD post hoc analysis applied to correct for multiple comparisons $(\mathrm{C}, \mathrm{E}, \mathrm{I}, \mathrm{K}) ;{ }^{*} \mathrm{P}<.05,{ }^{* * *} \mathrm{P}<0.001$ (For ANOVA, only comparison between pre and laser shown, see Supplementary Table 1 for detailed statistics). Arrowhead in firing 
bioRxiv preprint doi: https://doi.org/10.1101/2021.11.12.468404; this version posted November 13,2021 . The copyright holder for this preprint (which was not certified by peer review) is the author/funder, who has granted bioRxiv a license to display the preprint in perpetuity. It is made available under aCC-BY-NC-ND 4.0 International license.

rate and velocity traces corresponds to $0 \mathrm{sp} / \mathrm{s}$ and $1 \mathrm{~cm} / \mathrm{s}$, respectively. Bar plots and average firing rate traces show mean \pm SEM. 